University of Louisville

ThinkIR: The University of Louisville's Institutional Repository

Electronic Theses and Dissertations

$12-2011$

\title{
Age-associated periodontal bone loss in normal and TLR2- or MyD88-deficient mice.
}

Paul A. Ciero 1986-

University of Louisville

Follow this and additional works at: https://ir.library.louisville.edu/etd

\section{Recommended Citation}

Ciero, Paul A. 1986-, "Age-associated periodontal bone loss in normal and TLR2- or MyD88-deficient mice." (2011). Electronic Theses and Dissertations. Paper 252.

https://doi.org/10.18297/etd/252

This Master's Thesis is brought to you for free and open access by ThinkIR: The University of Louisville's Institutional Repository. It has been accepted for inclusion in Electronic Theses and Dissertations by an authorized administrator of ThinkIR: The University of Louisville's Institutional Repository. This title appears here courtesy of the author, who has retained all other copyrights. For more information, please contact thinkir@louisville.edu. 


\title{
AGE-ASSOCIATED PERIODONTAL BONE LOSS IN NORMAL AND TLR2- OR MYD88-DEFICIENT MICE
}

\author{
Paul A. Ciero
}

B.S., University at Buffalo, the State University of New York, 2009

\author{
A Thesis \\ Submitted to the Faculty of the \\ University of Louisville School of Dentistry \\ In Partial Fulfillment of the Requirements \\ For the Degree of \\ Master of Science \\ Department of Oral Biology \\ School of Dentistry \\ University of Louisville \\ Louisville, Kentucky
}

December 2011 


\title{
AGE-ASSOCIATED PERIODONTAL BONE LOSS IN NORMAL AND TLR2- OR MYD88-DEFICIENT MICE
}

\author{
Paul A. Ciero \\ B.S., University at Buffalo, the State University of New York, 2009
}

Thesis Approved on

November 21, 2011

By the following Thesis Committee

Dr. George Hajishengallis (Chairman)

Dr. Pascale Alard 


\section{DEDICATION}

I would like to dedicate this work to my parents, for all of their support. 


\section{ACKNOWLEDGEMENTS}

My very deepest gratitude goes to my mentor, Dr. George Hajishengallis, for all his time and guidance throughout my graduate studies. His accomplishments are tremendous inspirations to me, my fellow laboratory members, and the scientific community at large. I am truly honored to have been a member of his laboratory.

I am also deeply grateful for the guidance and efforts of Dr. Shuang Liang, who has also been a significant mentor in my studies. He has made countless contributions to my intellectual growth and development of skills in the laboratory.

I would also like to thank Dr. Pascale Alard, my professor and committee member, for her time and valuable input into this project.

Finally, I would like to thank my program director, Dr. David Scott, who has been helpful in so many ways, and the Center for Oral Health and Systemic Disease at the University of Louisville School of Dentistry, which has been a wonderful place to perform this research. Enrolling in graduate school here was a fantastic decision. 


\title{
ABSTRACT
}

\section{AGE-ASSOCIATED PERIODONTAL BONE LOSS IN NORMAL AND TLR2- OR MYD88-DEFICIENT MICE}

\author{
Paul A. Ciero
}

November 21, 2011

\begin{abstract}
Age-related alterations in innate immunity are poorly understood. The identification of those mechanisms, which are dysfunctional in old age, will shed light on potential therapeutic strategies for chronic inflammatory diseases prevalent in the elderly, such as periodontitis. Mice naturally develop chronic periodontitis as a function of age, which is characterized by periodontal bone loss. TLR2, a pattern-recognition receptor of leukocytes which mediates inflammatory responses in the periodontium, was expressed at higher levels in the gingivae of old mice ( $\geq 18$ months) compared with young mice ( 8 to 10 weeks). MyD88 is a signaling adaptor protein for TLR2 and other TLRs. We thus hypothesized that age-associated periodontal bone loss may be mediated through TLR2 and MyD88 and tested this hypothesis in appropriate gene knockout mice. Periodontal bone levels were measured as the distance from the cementoenamel junction to the alveolar bone crest. Aged $T L R 2^{-/-}$and $M y D 88^{-/-}$
\end{abstract}


mice developed less periodontal bone loss compared to age-matched wild-type mice. These results indicate that TLR2 and its adaptor MyD88 contribute to periodontal bone loss in aged mice, implicating these molecules as potential targets for drug therapies in the treatment of periodontitis. 


\section{TABLE OF CONTENTS}

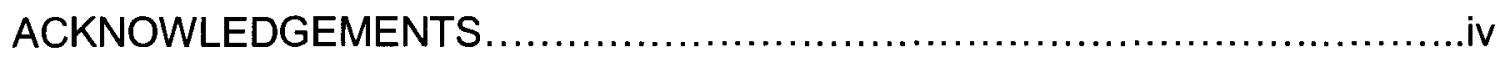

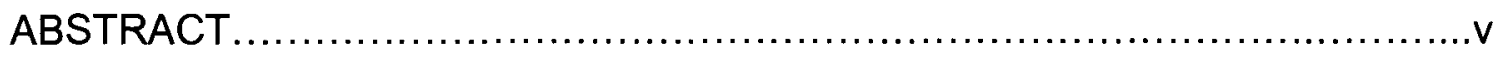

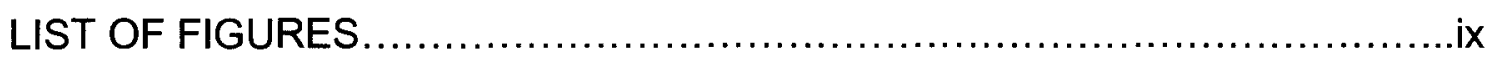

CHAPTER I:

INTRODUCTION

BROAD PROBLEM: PERIODONTITIS AND AGE.......................

ETIOLOGY AND PATHOGENESIS OF PERIODONTITIS .................

THE AGING INNATE IMMUNE SYSTEM.....................................

INSIGHTS FROM IN VIVO STUDIES .............................9

THE ROLE OF TLR2 IN PERIODONTITIS PATHOLOGY...............15

THE ROLE OF MYD88 IN TLR2- AND TLR4- SIGNALING ...............22

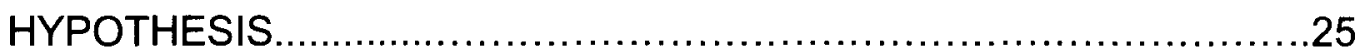

CHAPTER II:

METHODS AND MATERIALS

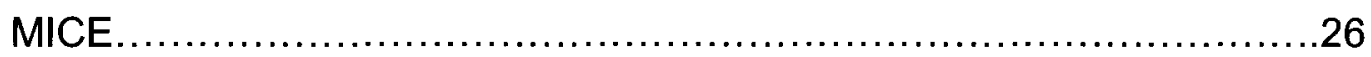

DETERMINATION OF PERIODONTAL BONE LOSS ...................26



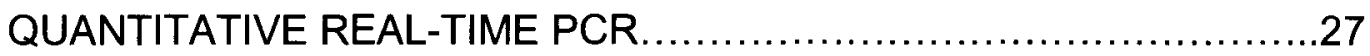

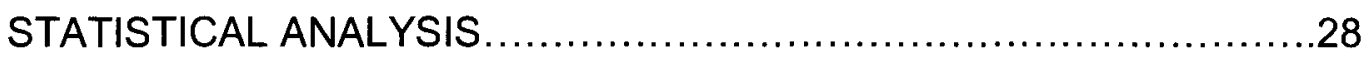


CHAPTER III:

RESULTS

TLR2 $2^{--}$MICE DEVELOP LESS AGE-ASSOCIATED BONE LOSS

THAN WILD-TYPE CONTROLS ..........................................29

ORAL ANAEROBIC BACTERIAL LOAD IS INCREASED IN

AGED TLR2 $2^{-/}$MICE.

GINGIVAL EXPRESSION OF INNATE INFLAMMATORY

MEDIATORS INDICATES LESSENED INFLAMMATION IN

AGED TLR2 $2^{-/}$MICE

MYD88 ${ }^{-/}$MICE DEVELOP LESS AGE-ASSOCIATED BONE LOSS

THAN WILD-TYPE CONTROLS

ORAL ANAEROBIC BACTERIAL LOAD IS DECREASED IN

AGED MYD $88^{-/-}$MICE.

GINGIVAL EXPRESSION OF INNATE INFLAMMATORY

MEDIATORS INDICATES ACTIVATION OF TRIF-DEPENDENT

PATHWAY IN AGED MYD88 ${ }^{-/}$MICE

CHAPTER IV:

DISCUSSION AND CONCLUSIONS

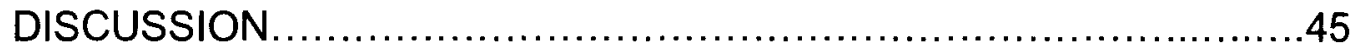

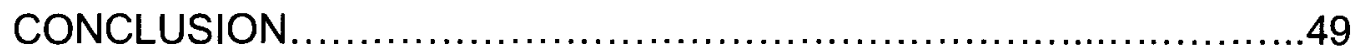

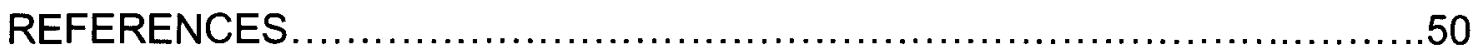

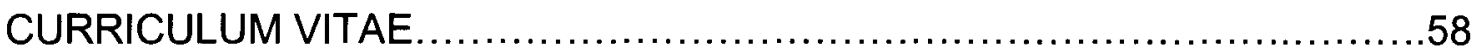




\section{LIST OF FIGURES}

1. Periodontal bone loss in mice as a function of age .......................11

2. Relative expression of innate immune receptors in the gingivae of

young and old mice.

3. TLR adaptor molecules and signaling pathways ........................24

4. Age-associated periodontal bone loss in Normal and $T L R 2^{-/}$mice .......30

5. Representative images of CEJ-ABC distances in wild-type and $T L R 2^{-/}$mice at 18 months

6. Oral anaerobic bacterial load is increased by TLR2 deficiency in aged mice

7. mRNA expressions in the gingivae of old $T L R 2^{-/}$mice relative to wild-type controls .36

8. Age-associated periodontal bone loss in Normal and MyD88 mice. .38

9. Representative images of CEJ-ABC distances in wild-type and $M y D 88^{-/-}$mice at 18 months

10. Oral anaerobic bacterial load is decreased by MyD88 deficiency in aged mice.

11. mRNA expressions in the gingivae of old $M y D 88^{-1}$ mice relative to wild-type controls. 


\section{CHAPTER I:}

\section{INTRODUCTION}

\section{BROAD PROBLEM: PERIODONTITIS AND AGE}

Periodontitis is a chronic inflammatory disease that leads to destruction of the tissues supporting the teeth. It is the leading cause of tooth loss in adults, and one of the most common infection-driven chronic disorders in humans, afflicting about $30 \%$ of the adult population (Oliver et al., 1998). In addition, it is associated with other conditions including, but not limited to, cardiovascular diseases, type 2 diabetes, adverse pregnancy outcomes, respiratory diseases, and rheumatoid arthritis (Cullinan et al., 2009).

Periodontitis is one of several age-associated diseases. Epidemiologic studies have revealed that the prevalence and severity of periodontitis increase with age (Oliver et al., 1998; van der Velden, 1991). Furthermore, the elderly population is increasing, making age-associated diseases a high priority for researchers (Dounis et al., 2010; Winker and DeAngelis, 2010). 


\section{ETIOLOGY AND PATHOGENESIS OF PERIODONTITIS}

In terms of etiology, periodontitis is an infectious disease caused by select species of the mouth's indigenous microbiota. These bacteria exist in a highly organized plaque biofilm on the tooth surface. The quantitative and qualitative composition of the biofilm are of etiologic importance, both of which change as disease progresses. Its composition in periodontal health is generally characterized by gram-positive facultative anaerobes, while that in disease is generally characterized by a shift to gram-negative anaerobes (Socransky and Haffajee, 2005). While at least 800 bacterial species exist in the biofilm (Filoche et al., 2010), a relatively small number are believed to be the etiologic agents of periodontitis. Those which are believed to play prominent roles include Porphyromonas gingivalis, Treponema denticola, Prevotella intermedia, Aggregatibacter actinomycetemcomitans, Tannerella forsythia, and Fusobacterium nucleatum (Filoche et al., 2010; Socransky and Haffajee, 2005). Furthermore, the presence of certain periodontal pathogens in combination with others is believed to provide a synergy that increases their pathogenicity (Kinane and Hajishengallis, 2009).

The extension of the biofilm into the gingival sulcus begins the series of events that mediate periodontal disease. In reaction to the presence of pathogens and their metabolic products in the gingival sulcus, host cells including neutrophils, epithelial cells and resident macrophages will signal to initiate the inflammatory response. This results in the influx of inflammatory infiltrate from the gingival plexus of blood vessels into the gingival sulcus via the junctional 
epithelium, subjacent to the sulcus. The most abundant cellular component of this fluid is neutrophils, however also present are mononuclear phagocytes and lymphocytes, as well as complement components (Delima and Van Dyke, 2003). While the pathogenesis of periodontal disease is complex and still largely undiscovered, it is generally accepted that the chronic nature of the host inflammatory response is the main factor in causing tissue damage, rather than the direct effects from the pathogens themselves. This is a result of the various methods these pathogens have developed in order to survive in this environment.

Neutrophils will attempt to phagocytose the bacteria of the advancing plaque front, then utilize their intracellular killing mechanisms. Phagocytosis may be enhanced by pathogens opsonized by antibodies or complement fragments. However, some periodontal pathogens have developed ways to resist phagocytosis using virulence factors such as polysaccharide capsules, or avoid phagocytes altogether by gaining entry into host cells (Dennison and Van Dyke, 1997).

Another method of fighting periodontal pathogens is extracellularly, via neutrophil degranulation, which is utilized in the presence of large quantities of bacteria in the gingival sulcus. When neutrophils degranulate, they release granular enzymes such as collagenase, elastase, and gelatinase, as well as superoxide and oxygen radicals, and nitric oxides. These products do not discriminate between the bacteria and the host tissues. Thus, periodontal tissue destruction will result from prolonged exposure (Lee et al., 1995). 
A major characteristic of periodontitis is alveolar bone loss. The field which studies the interactions of the immune system and bone metabolism is called osteoimmunology. In periodontitis, chronic inflammation will produce boneresorptive cytokines, notably TNFa and IL-1 $\beta$. TNF $\alpha$ can directly stimulate osteoclast formation, thereby inducing bone resorption, and also indirectly by stimulating RANKL production (Graves et al., 2011). IL-1 $1 \beta$ can also induce osteoclastogenesis both directly and indirectly through RANKL (Lorenzo et al., 2008). The location of the pathogens and the duration of their persistence determine clinical outcomes, and when the bacterial insult is deeper in the periodontal pocket, in approximation to the alveolar bone for prolonged periods, the result is alveolar bone loss (Graves et al., 2011).

Adaptive immunity is also likely to play a role in periodontitis. The nature of the CD4+ T-cell response may be a critical factor in determining disease progression (Teng, 2003). Cytokines produced may favor a Th1- or Th2-biased response, and studies have shown that Th2 responses are associated with progressive lesions, while Th1 responses are associated with early stable lesions (Gemmell et al., 2002; Gemmell and Seymour, 2004). In addition, the Th1associated cytokines IL-12 and IFNy are shown to inhibit osteoclastogenesis (Gowen and Mundy, 1986; Gowen et al., 1986; Horwood et al., 2001). However, there are limitations in the Th1/Th2 paradigm for explaining periodontal disease pathogenesis, which must be re-examined in the context of the more recently discovered Th17 cells, which have been shown to promote osteoclastogenesis, but also to offer protective effects (Gaffen and Hajishengallis, 2008). 
THE AGING INNATE IMMUNE SYSTEM

As mentioned, the prevalence and severity of periodontitis increase with age (Oliver et al., 1998; van der Velden, 1991). Furthermore, this is likely due to an altered immune system rather than simply a cumulative effect (Fransson et al., 1996). Therefore, research has sought to define which aspects of the immune system become dysregulated in order to develop therapeutic strategies to counteract age-associated diseases.

The immune system as a whole is known to dysfunction with age, a phenomenon that has been termed, "immunosenescence." Age-associated defects have been noted in all types of immune cells, impacting on their numbers, function, or both (Gomez et al., 2008). This inhibits the body's ability to recover from infections and injuries; thus, the elderly are more susceptible to chronic inflammatory diseases.

It is well-known that aging is associated with a decline in the functions of acquired immunity. For example, age-associated decreases in the production of naïve lymphocytes and the maintenance of memory lymphocytes have been observed (Nan-ping, 2006).

However, the effects of aging on the innate immune system are poorly understood. This is largely because immunologists underestimated its role in shaping the adaptive response, and therefore its overall significance, until relatively recently (Fearon, 1997). It is now known that in addition to providing initial defense, the innate response controls the adaptive component in a variety 
of different ways. This includes the ability of Toll-like receptors (TLRs) to recognize and respond to pathogens with a fair degree of specificity (Yamamoto et al., 2004).

Advanced age is associated not only with losses in immune function, but with over-activation as well, implying a complex overall dysregulation rather than deficiencies alone. The overall increased pro-inflammatory status seen in aged humans has been termed "inflamm-aging." Though it is not clear what exactly causes this phenomenon, it likely results from some age-associated intrinsic defects in the innate immune system, which is responsible for controlling inflammation (Franceschi et al., 2000; Solana et al., 2006).

Studies have thus sought to determine age-associated defects in the cells of the innate immune system, especially neutrophils and macrophages, which play essential roles in inflammatory diseases. Due to conflicting results, there are still consensus conclusions to be made in this field, and some reports conclude that many functions are maintained (Liang et al., 2009). Nevertheless, several alterations in these cells have been reported. These studies have been recently reviewed in detail by Gomez (Gomez et al., 2008), Hajishengallis (Hajishengallis, 2010), and Shaw (Shaw et al., 2010). In summary, circulating neutrophil numbers are maintained with age, unlike monocyte/macrophage numbers, which have been shown to increase. Functionally, neutrophils and macrophages have both been reported to experience impaired chemotaxis, phagocytosis, and reactive oxygen species production. Neutrophils have also shown reduced recruitment of receptors to membrane lipid rafts, which can have several diverse effects on 
signaling (Fulop et al., 2004). The reviews also report altered cytokine production, nitric oxide production, antigen presentation, and expression of certain receptors involved in inflammation, including the C5aR (Liang et al., 2009) in macrophages. Reports have also indicated age-associated defects in dendritic cells, natural killer cells, and natural killer T-cells. (Shaw et al., 2010).

These types of defects could inhibit the host's ability to control microbial infections. For instance, neutrophils from an aged individual may fail to contain a periodontal infection due to its intrinsically impaired antimicrobial abilities, which would result in the recruitment of even more neutrophils with impaired functions. Thus, the environment would become chronically inflamed, and the eventual release of toxic substances from these neutrophils could cause tissue damage. (Hajishengallis, 2010).

While it is important to continue studying age-associated intrinsic defects in immune cells, this research provides only limited insights into ways to counteract age-related diseases. The ways in which these defects influence the host response and disease progression are more complex. Immune cells interact with their tissue microenvironment, which is also susceptible to age-associated changes. In fact, age-associated changes in stromal cell function and imbalances in cytokines and hormones have been reported to affect the immune response (Stout and Suttles, 2005).

Thus, age-related influences on innate immunity are tissue-specific and disease-specific. Experiments done in vitro cannot accurately replicate this, and 
in vivo experiments may provide better insight into ways we may counteract agerelated factors contributing to periodontitis because they take into account both intrinsic and extrinsic factors. 


\section{INSIGHTS FROM IN VIVO STUDIES}

Animal models serve as an essential tool for testing hypotheses that, due to ethical considerations, cannot be tested in humans. The mouse model has been a successful tool in studying infection-driven inflammatory diseases including periodontitis, owing to the substantial background information on their immune systems and the availability of gene knockout mice, as well as their affordability relative to other animal models (Graves et al., 2008). This allows us to test hypotheses in vivo regarding processes taking place in the periodontium including bacterial colonization, host-bacteria interactions, and clinical manifestations of disease such as loss of connective tissue attachment and bone resorption (Graves et al., 2008).

Periodontitis is typically induced in mice using oral gavage with human periodontal pathogens such as Porphyromonas gingivalis, Tannerella forsythia, and Aggregatibacter actinomycetemcomitans, which is evidenced by alveolar bone loss (Baker et al., 2000; Garlet et al., 2006; Hajishengallis et al., 2007;

Sharma et al., 2005). While young sham-infected mice typically do not develop periodontitis, studies showed that young mice with P/E-selectin deficiency (Niederman et al., 2001) or impaired neutrophils (Beertsen et al., 2008) did in fact develop early-onset periodontitis. This indicated that the experimental mice contained potential periodontal pathogens despite claims by animal vendors that their mice are pathogen-free. Indeed, these studies showed that periodontal inflammation and bone loss in these mice were prevented by antibiotic treatment (Beertsen et al., 2008; Niederman et al., 2001). 
Due to these revelations and the association of old age with periodontitis, it was suspected that mice could develop naturally-induced periodontitis as a function of age, without oral infections with human periodontal pathogens. Indeed, mice aged 18 months showed significant alveolar bone loss compared with young mice at 8-10 weeks (Figure 1) (Liang et al., 2010). 


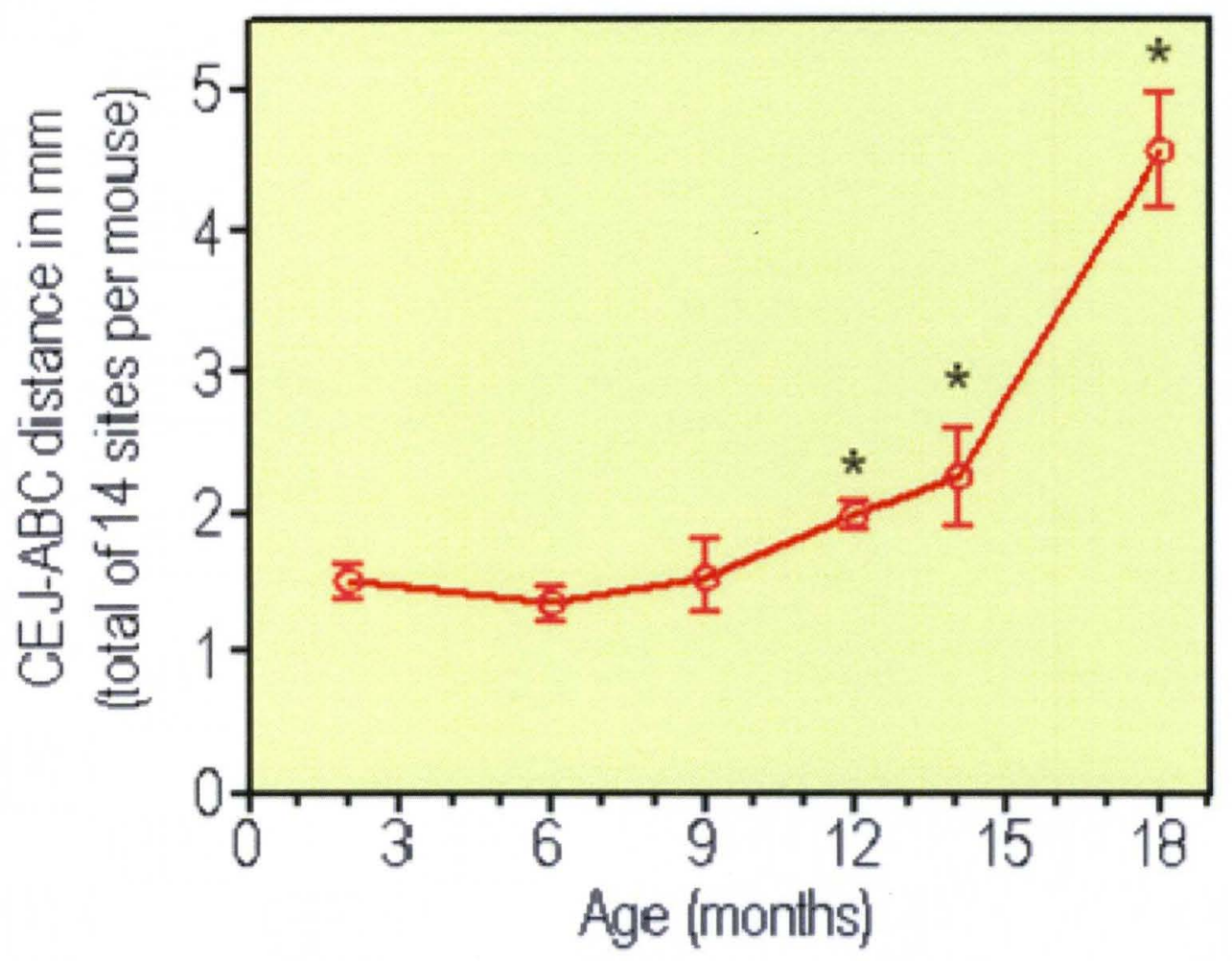

Figure 1: Periodontal bone loss in mice as a function of age. Young BALB/C mice (8-10 weeks of age) and old ( $\geq 18$ months) and mice of intermediate ages $(6,9,12$ and 14 months) were used to determine their periodontal bone levels. No oral gavage was administered in these mice. The distance (in $\mathrm{mm}$ ) from the cementoenamel junction (CEJ) to the alveolar bone crest $(A B C)$ was measured in 14 predetermined maxillary buccal sites, and the readings were totaled for each mouse. The data are means \pm SD ( $n=5$ mice). Liang et al, J. Periodont. Res. (2010). 
Consistently, the gingivae of these old mice displayed increased expression of IL-1 $\beta$, TNF- $\alpha$, and IL-17A, which are mediators of inflammation and bone loss (Liang et al., 2010). Furthermore, age-associated expressions of inflammatory mediators were not observed in the spleens of these mice, indicating the periodontal environment as the influential factor in these observations, rather than global age-dependent changes (Liang et al., 2010). This aging model of periodontitis allows us to study mechanisms in the pathology of chronic periodontitis, and the current investigation aims to use this model accordingly.

In addition to the expression of aforementioned inflammatory mediators (IL-1 $\beta$, TNF- $\alpha$, and IL-17A ), Liang et al. also investigated the expression of innate immune receptors in the gingivae of the young and old mice. Those innate immune receptors which were upregulated in the gingivae of old mice compared with young included the Toll-Like Receptor 2 (TLR2) and its functionally associated co-receptor CD14 (Figure 2) (Liang et al., 2010). 


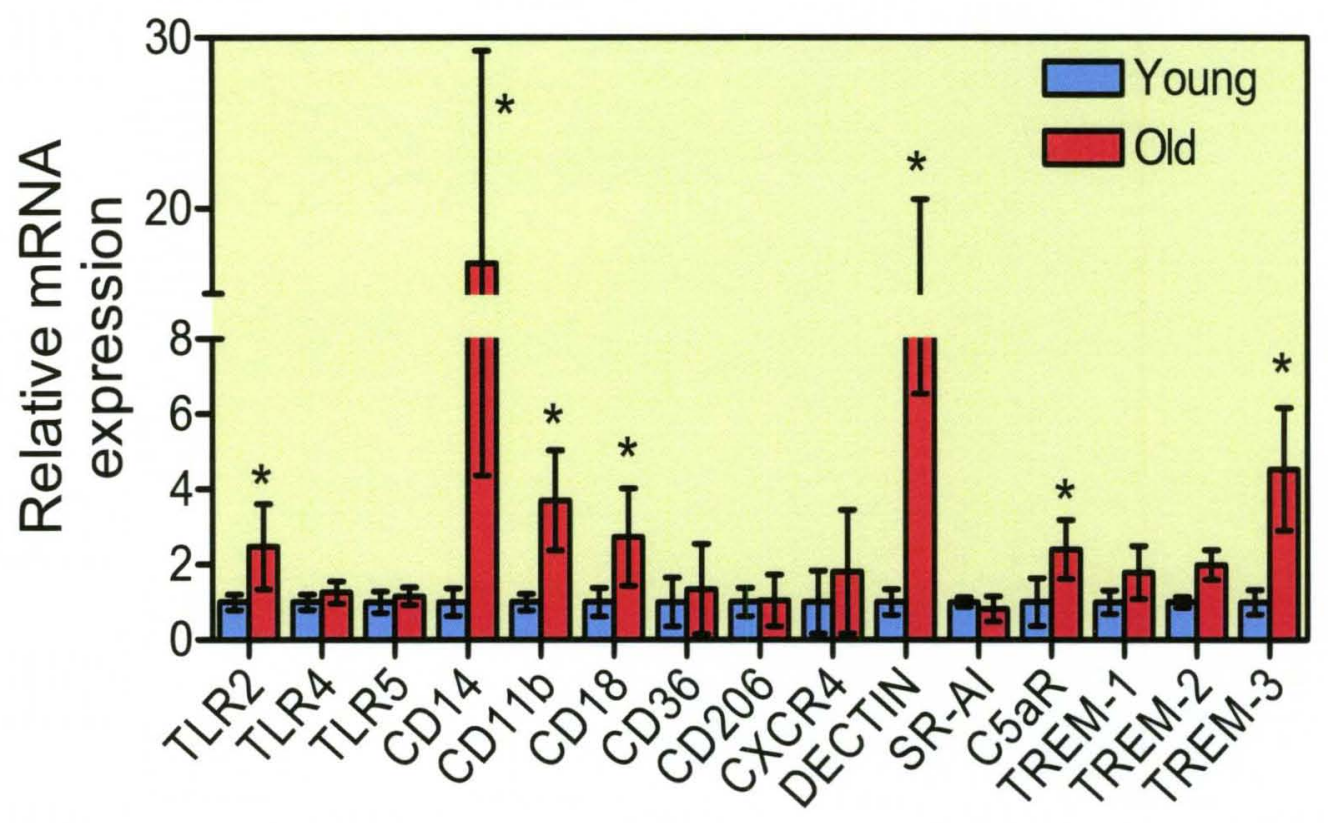

Figure 2: Relative expression of innate immune receptors in the gingivae of young and old mice. Quantitative real-time PCR ( $q P C R$ ) was used to determine gingival mRNA expression levels for the indicated receptors (normalized against GAPDH mRNA levels). The gingivae used were excised from young (8-10 wk of age) and old BALB/c mice ( $\geq 18$ mo of age). Results are shown as fold induction relative to young. Each data point represents the mean \pm SD of 10 separate expression values, corresponding to qPCR analysis of total gingival RNA from individual mice. A minimum of 2-fold difference was a requirement for further testing of statistical significance. Asterisks indicate statistically significant differences $(p<0.05)$ between old and young mice. TLR2 mRNA expression was increased in the old mice relative to the young. Liang et al, J. Periodont. Res. (2010). 
These findings imply the likelihood that TLR2 signaling is contributing to age-associated periodontal inflammation. A large body of work consistently indicates TLR2 as being a key receptor in human periodontitis, which is outlined in the next section. 


\section{THE ROLE OF TLR2 IN PERIODONTITIS PATHOLOGY}

The Toll-like receptors (TLRs) are a family of pattern recognition receptors that play critical roles in the innate immune response to microbes. They are type 1 integral membrane glycoproteins expressed on various immune cells including macrophages, dendritic cells, neutrophils, B-cells, and natural killer cells, as well as non-immune cells such as mucosal epithelial cells, endothelial cells, and fibroblast cells. They recognize and respond to pathogen-associated molecular patterns (PAMPs), which are molecules present on microbes but absent in mammalian cells, allowing the host's initial distinction between "self" from "nonself". TLRs contain an extracellular leucine-rich repeat domain, a transmembrane domain, and a cytoplasmic TIR (Toll/interleukin-1 receptor) domain, which is essential for signaling. In response to ligand binding by TLRs, the TIR domain initiates signaling cascades which ultimately result in the activation of transcription factors such as NFKB, AP-1, IRF-3, and IRF-7. The NFKB and AP-1 transcription factors promote the expression of genes encoding molecules of the innate immune response such as inflammatory cytokines, chemokines, and endothelial adhesion molecules. On the other hand, IRF-3 and IRF-7 primarily promote the production of type 1 interferons.

TLRs are classified into groups based on the types of ligands they recognize, and they are differentially located in the cell. There are 11 known TLRs expressed in humans and 13 in mice (Kawai and Akira, 2007). TLR1, TLR2, TLR4, TLR5, and TLR6 appear on the plasma membrane and TLR3, TLR7, TLR8, and TLR9 are expressed on endosomes. The capacity of TLRs to 
recognize a wide range of ligands is enhanced by their ability to homodimerize, heterodimerize, and to integrate coreceptors. They may recognize lipids, sugars, proteins, derivatives of these molecules, and nucleic acids (Kumar et al., 2009a).

TLRs play a key role in the periodontal immune response, as evidenced by the infiltration of TLR-expressing inflammatory cells and the increased TLR expression in diseased gingivae compared with healthy gingivae (Mori et al., 2003; Ren et al., 2005).

Research is actively identifying TLR ligands, and conflicting results delay consensus conclusions. TLR2 and TLR4, however, have been identified as the principal receptors for bacterial cell wall components. A large body of work focuses on the roles of these two receptors in periodontal disease (Burns et al., 2006; Folwaczny et al., 2004; Hajishengallis et al., 2009; Hou et al., 2000; Kikkert et al., 2007; Mori et al., 2003; Sun et al., 2010; Yoshioka et al., 2008).

TLR4 functions as a homodimer and is the most characterized of all TLRs (McCoy and O'Neill, 2008). It functions in association with the accessory molecules LBP (LPS binding protein), CD14, and MD-2 (Akashi-Takamura and Miyake, 2008; Shimazu et al., 1999; Wright et al., 1989; Wright et al., 1990). Among its ligands are lipopolysaccharide (LPS) from Gram-negative bacteria (Kumar et al., 2009a; Takeuchi et al., 1999). It has been shown that $T L R 4^{-/-}$mice are protected from bone loss following a mixed anaerobic infection (Hou et al., 2000), implying its involvement in periodontitis. 
TLR2 can recognize an array structurally diverse PAMPs, including proteins, lipoproteins, lipopeptides, glycolipids, polysaccharides, and even complete pathogens (Kumar et al., 2009a). To name some ligands from recent reviews, TLR2 recognizes peptidoglycan, LTA, LPS of Porphyromonas gingivalis, LPS of Leptospira, mycobacterial lipoarabinomannan, glycosylphosphatidyl inosital mucin from Trypanosoma, hemagglutinin from the measles virus, fungal zymosan, and phospholipomannan from Candida (Brown et al., 2010; Kawai and Akira, 2007; Kumar et al., 2009a). The diversity of TLR2 recognition owes partially to its ability to heterodimerize with TLR1 or TLR6 to recognize triacyl or diacyl lipoproteins, respectively (Takeuchi et al., 2001; Takeuchi et al., 2002) as well as its associations with accessory molecules CD14 and CD36 (AkashiTakamura and Miyake, 2008). It has also been shown to dimerize with TLR10, though the ligands for this heterodimer are unknown (Hasan et al., 2005). TLR2 has been reported to recognize the broadest range of bacterial PAMPs, and its precise ligands are continually being discovered and debated (Zähringer et al., 2008).

Regarding the prevalence of TLR2 activation in the periodontium as opposed to TLR4, recent evidence implicates TLR2 as the primary TLR stimulated by Gram-negative periodontal bacteria. Kikkert et al. demonstrated that sonicates of the gram-negative periodontal pathogens $P$. gingivalis, $P$. intermedia, F. nucleatum, and $T$. forsenthis exclusively stimulated TLR2 while $A$. actinomycetemcomitans stimulated both TLR2 and TLR4 (Kikkert et al., 2007). 
Studies have also shown that $T$. denticola activates TLR2, rather than TLR4 (Asai et al., 2003; Nussbaum et al., 2009; Ruby et al., 2007).

Studies regarding $P$. gingivalis are especially significant. This pathogen successfully subverts the immune response (Hajishengallis, 2009) en route to triggering community-wide changes in the biofilm disruptive to host-microbial homeostasis; thus, this "keystone species" plays an essential role in inflammatory bone loss (Hajishengallis et al., 2011). Studies have indicated that P. gingivalis stimulates both TLR2 and TLR4 through various components, including its LPS and fimbriae, but also antagonizes TLR4 (Asai et al., 2001; Darveau et al., 2002; Hajishengallis et al., 2004; Teng, 2006). However, the exact ligands are still a matter of debate. Nevertheless, Burns et al. demonstrated that TLR2 is responsible for the innate response to $P$. gingivalis and that TLR2 deficiency, but not TLR4 deficiency, attenuates alveolar bone resorption in vivo (Burns et al., 2006).

Additionally, Ukai et al. reported that macrophage-elicited osteoclastogenesis in response to bacterial stimulation requires TLR2-dependent TNFa production (Ukai et al., 2008), further implying TLR2 activation as a principle PRR in periodontal bone loss.

In addition to inflammatory signaling, TLRs likely impact periodontitis in other ways. Though they are not phagocytic receptors, studies have revealed their importance for each stage of phagocytosis (McCoy and O'Neill, 2008; Underhill and Gantner, 2004). In addition, TLR signaling plays crucial roles in 
antigen processing and presentation (McCoy and O'Neill, 2008). They can promote B7 costimulatory molecules as well as MHC class II molecules (Iwasaki and Medzhitov, 2004).

TLR-mediated signaling by antigen-presenting cells, especially dendritic cells, can also modulate the adaptive response through its induction of immunomodulatory cytokines (Iwasaki and Medzhitov, 2004). As mentioned previously, studies have shown that in periodontitis, Th2 responses are associated with progressive lesions, while Th1 responses are associated with early stable lesions (Gemmell et al., 2002; Gemmell and Seymour, 2004). TLR2 has relevance to this pattern; studies indicate that TLR4 stimulation promotes a Th1 response through production of IL-12p70, IFNy, and other Th1-associated molecules whereas TLR2 stimulation tends to promote a Th2 response, due in part to its failure to induce the IL-12p35 subunit (Goriely et al., 2008; Hirschfeld et al., 2001; Re and Strominger, 2001). Therefore, one can infer that the periodontal bacteria dictate the nature of the adaptive response, and therefore the progression of disease, through their specificities as TLR agonists. Thus, TLR2 can contribute to disease progression through its shaping of the adaptive response.

TLR2 is also involved in periodontal disease pathogenesis through its interactions with the complement system, which is also activated in periodontitis (Delima and Van Dyke, 2003). The signaling pathways of complement components and TLRs can engage in crosstalk, an important immune function under normal conditions. Certain pathogens in turn have developed methods to 
exploit these crosstalk pathways to promote their own survival. TLR2 is utilized in this sense by periodontal pathogens.

TLR2 engages in crosstalk with C5aR, which was also differentially upregulated in the gingivae of old mice (Figure 2) (Liang et al., 2010). Furthermore, C5aR-deficient mice are protected from age-associated periodontal bone loss, implicating C5aR in age-associated periodontitis (Liang et al., 2011). TLR2-C5aR crosstalk is exploited by $P$. gingivalis, which not only activates TLR2, but cleaves $\mathrm{C} 5$ through the action of its gingipains, thereby inducing the release of excessive amounts of the anaphylatoxin $\mathrm{C} 5 \mathrm{a}$, the ligand for $\mathrm{C} 5 \mathrm{aR}$ (Wingrove et al., 1992). This crosstalk exploitation can promote the survival of $P$. gingivalis in more than one way. First, TLR2-C5aR crosstalk in macrophages will cripple cellular immunity through inhibition of TLR2-dependent IL-12p70 production. The MEK-ERK1/2 pathway is implicated in this C5aR-mediated regulatory pathway, which is selective for IL-12p70; this crosstalk also produces excessive proinflammatory and bone-resorptive cytokines such as IL-1 $1 \beta$, IL-6, and TNF- $\alpha$ (Liang et al., 2011). Secondly, TLR2-C5aR crosstalk can increase cyclic adenosine monophosphate (cAMP) concentrations in macrophages, which promotes a cAMP-dependent protein kinase $A(P K A)$ signaling pathway that ultimately prevents iNOS production (Wang et al., 2010).

Furthermore, activation of TLR2-CXCR4 crosstalk by $P$. gingivalis inhibits iNOS production in the same cAMP-dependent manner as TLR2-C5aR crosstalk does (Hajishengallis et al., 2008), and these two crosstalk pathways can even act synergistically (Wang et al., 2010). 
Finally, P. gingivalis and Mycobacterium tuberculosis (and potentially other pathogens) exploit TLR2-complement receptor 3 (CR3) interactions for intracellular entry, inhibition of IL-12p70, and enhanced persistence in macrophages (Hajishengallis et al., 2007; Hajishengallis, 2009; Wang et al., 2007). CD11b and CD18, which heterodimerize to form CR3 (CD11b/CD18), were also differentially upregulated in the gingivae of old mice (Figure 3), suggesting the possibility that mouse periodontal bacteria are exploiting this pathway (Liang et al., 2010).

Though $P$. gingivalis is the pathogen of interest in these studies, and TLR2 the receptor of interest, it is likely that other oral pathogens exploit these crosstalk mechanisms in periodontitis, or similar, yet undiscovered ones to promote their virulence, given the novelty and importance of this specific field (Hajishengallis and Lambris, 2011).

Despite the lack of knowledge regarding the bacterial profile in the periodontium of the aged, diseased mice studied by Liang et al. (Liang et al., 2010), the differential up-regulation of TLR2 in comparison to other PRRs, including TLR4 (Figure 2), in the gingivae of the aged mice is consistent with the conclusion that TLR2 signaling is a critical contributor in periodontitis pathology. 
THE ROLE OF MYD88 IN TLR2- AND TLR4- SIGNALING

MyD88 plays an essential role in TLR2-mediated inflammatory signaling. It is one of five adaptor proteins utilized in TLR signaling, in addition to MyD88adaptor-like (MAL; also known as TIRAP), TIR-domain-containing adapter protein inducing IFN $\beta$ (TRIF), TRIF-related adaptor molecule (TRAM), and sterile $\alpha-$ and armadillo-motif-containing protein (SARM). Different TLR groups use different combinations of these adapters, gifting the TLR-mediated response with even more specificity (O'Neill and Bowie, 2007).

Though TLR2 and TLR4 share many downstream signaling pathways inducing some of the same innate cytokines such as IL-1 and TNFa, there are also differences in their signaling capacities. TLR2 and TLR4 both use MAL in addition to MyD88; MAL links the TLRs to MyD88 (though some TLRs do not require MAL for this purpose). In addition, TLR4 utilizes TRIF and TRAM in an MyD88-independent pathway, with TRAM linking TLR4 with TRIF. Thus, TLR signaling can be broadly categorized into two pathways: the MyD88-dependent pathway, which is utilized by all TLRs except TLR3, and the MyD88-independent pathway, or TRIF-dependent pathway, which is utilized exclusively by TLR3 and TLR4 (Brown et al., 2010; Kumar et al., 2009a; O'Neill and Bowie, 2007).

In the MyD88-dependent pathway, a cascade of kinases involving members of the IRAK family, TRAF- 6 , and TAK1 are activated. This then initiates the MAP kinases and IkB kinases, which activate AP-1 and NFkB, respectively to promote the transcription of pro-inflammatory cytokines including TNF $\alpha$ and IL-1 $\beta$ 
(Brown et al., 2010). MyD88 is essential for inflammatory signaling; studies have shown unresponsiveness to ligands for both TLR2 and TLR4 in MyD88 ${ }^{--}$mice (Kawai et al., 1999; O'Neill and Bowie, 2007; Takeuchi et al., 2000).

In the MyD88-independent pathway, a cascade of kinases involving TRAF-3, TBK1 and IKKi ultimately activates the transcription factor IRF-3, which primarily promotes the production of type I interferons. However, this pathway can also promote inflammatory cytokine production because TRIF can activate TAK1. However, this occurs with delayed kinetics in comparison with that of the MyD88-dependent pathway (Brown et al., 2010; Kawai et al., 1999; Kumar et al., 2009b; Yamamoto et al., 2003). 


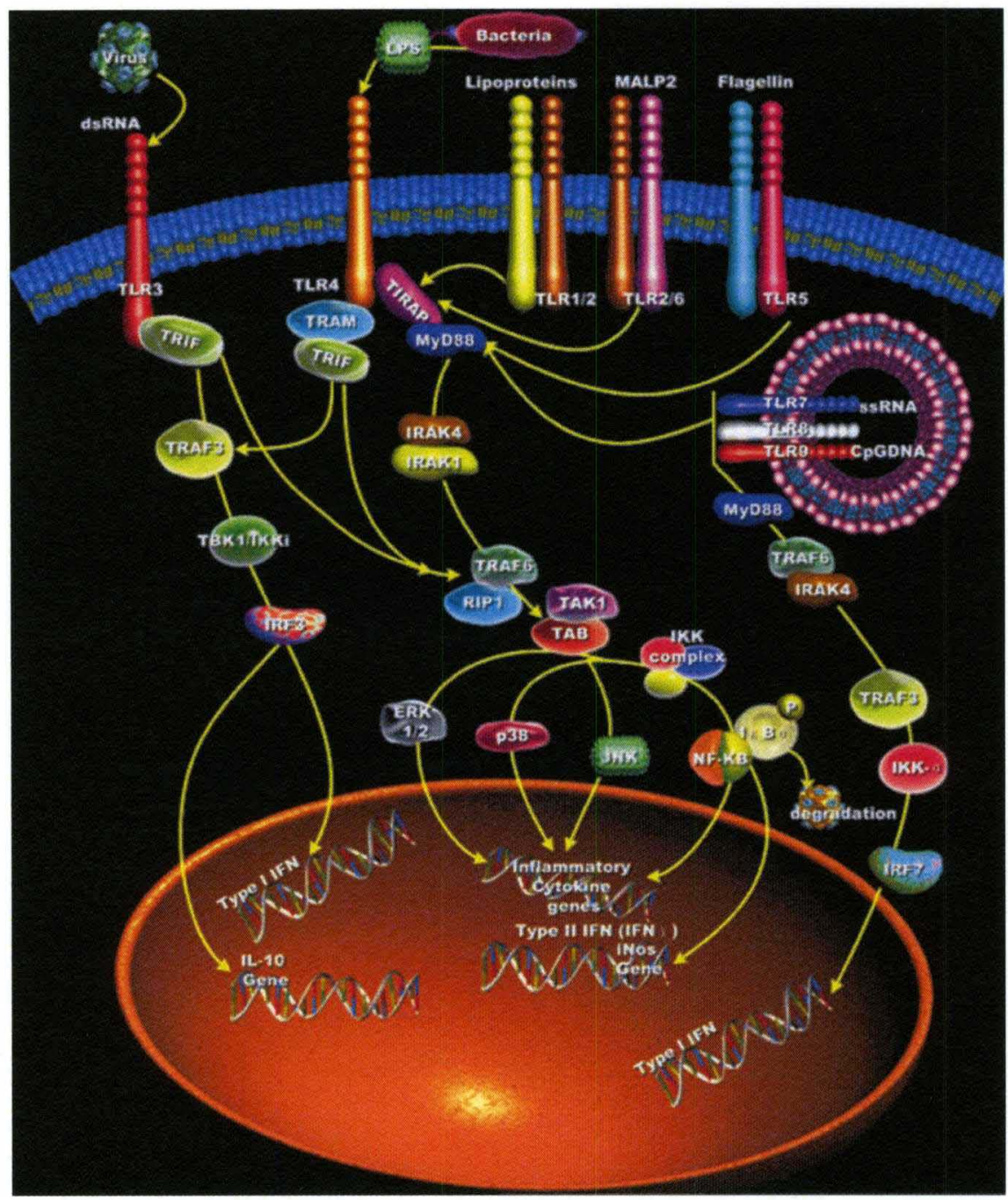

Figure 3. TLR adaptor molecules and signaling pathways. Signaling specificity of a given TLR can be imparted via the interaction of its TIR domain with MyD88, TIRAP, TRIF, or TRAM. All TLRs except TLR3 utilize MyD88 for the production of inflammatory cytokines. TLR2 and TLR4 recruit MAL/TIRAP and MyD88 to their TIR domain for activation of NF-KB and MAPKs that regulate inflammatory cytokine production. TLR4 can signal independently of MyD88 via the recruitment of TRAM and TRIF that activate IRF3 for the production of type I IFNs and delayed activation of MAPKs and NF-KB activity through TAK1. Brown et al., J. Dent. Res., (2010). 
HYPOTHESIS

Mice develop naturally occurring periodontitis as a function of age. TLR2 can induce pro-inflammatory signals and was found to be differentially upregulated in the gingivae of aged mice as compared to young controls. MyD88 is a major signaling adaptor acting downstream of TLR2. Therefore, I hypothesized that $T L R 2^{-1-}$ and $M y D 88^{-/-}$mice would be protected from ageassociated periodontal bone loss. This would implicate these molecules in age-associated periodontitis, and thus their potential as targets for therapies to counteract it. 


\section{CHAPTER II:}

\section{MATERIALS AND METHODS}

MICE

C57BL/6 wild-type, $T L R 2^{-/}$, and $M y D 88^{--}$, and BALB/C wild-type mice were obtained from The Jackson Laboratory. The $T L R 2^{-/-}$mice were originally C57BL/6 and we backcrossed them for nine generations onto a BALB/c genetic background before their use in these studies. Mice were raised to appropriate ages under specific-pathogen-free conditions in individually ventilated cages in the Barrier Animal Facility of the University of Louisville. All animal procedures described in this study were approved by the Institutional Animal Care and Use Committee, in compliance with established federal and state policies.

\section{DETERMINATION OF PERIODONTAL BONE LOSS}

Periodontal bone levels were assessed in defleshed maxillae under a dissecting microscope $(x 40)$ fitted with a video image marker measurement system (VIA-170K; Boeckeler Instruments) standardized for measurements in millimeters. Specifically, the distance from the cementoenamel junction (CEJ) to the alveolar bone crest $(A B C)$ was measured on 14 predetermined points on the 
buccal surfaces of the maxillary molars. To calculate relative bone loss (e.g. $T L R 2^{-/}$mice vs. wild-type controls, or old mice vs. young controls), the 14-site total CEJ-ABC distance for each mouse was subtracted from the mean CEJ-ABC distance of control mice. The results were expressed in $\mathrm{mm}$ and negative values indicated bone loss relative to controls.

\section{ORAL BACTERIA SAMPLING}

To assess the oral microbial burden, the murine oral cavity was sampled for 15 seconds using sterile paperpoints in contact with the gumlines. Serial dilutions of the paperpoint extracts were inoculated on GAM blood agar plates and grown anaerobically at $37^{\circ} \mathrm{C}$ for one week for CFU determination.

\section{QUANTITATIVE REAL-TIME PCR}

Immediately upon sacrificing, gingival tissue was excised from around the maxillary molars. Total RNA was extracted using the PerfectPure RNA cell kit ( 5 Prime, Fisher) and quantified by spectrometry (Nanodrop) at 260 and $280 \mathrm{~nm}$. The RNA was reverse-transcribed using the High-Capacity cDNA Archive kit (Applied Biosystems) and quantitative real-time PCR was performed using the ABI 7500 Fast System, according to the manufacturer's protocol (Applied Biosystems). TaqMan probes, sense primers, antisense primers for expression of genes examined in this study (Figures 7,11), or a housekeeping gene (GAPDH), 
were purchased from Applied Biosystems. Samples were denatured for 23 seconds at $95^{\circ} \mathrm{C}$ and annealed and extended at $60^{\circ} \mathrm{C}$ for 30 seconds following the manufacturer's protocol (Applied Biosystems) for a total of 40 cycles. Target genes vs. GAPDH were calculated as fold change using the relative quantitation formula, $2^{-\Delta \Delta C t}$.

\section{STATISTICAL ANALYSIS}

Data were evaluated by analysis of variance and the Dunnett multiplecomparison test using the InStat program (GraphPad Software, San Diego, CA). Where appropriate (comparison of two groups only), two-tailed $t$ tests were performed. A p value, 0.05 was taken as the level of significance. 


\section{CHAPTER III:}

\section{RESULTS}

\section{TLR2 ${ }^{--}$MICE DEVELOP LESS AGE-ASSOCIATED BONE LOSS THAN WILD- TYPE CONTROLS}

Mice develop naturally occurring periodontitis as a function of age. TLR2 can induce pro-inflammatory signals and was found to be differentially upregulated in the gingivae of aged mice as compared to young controls. Therefore, we investigated whether TLR2 deficiency attenuated age-associated periodontal bone loss. BALB/C and $T L R 2^{-/}$mice were raised under specificpathogen-free conditions, and then sacrificed at two time points: the young group ( 5 mice per group) at 8 weeks, and the old (16 mice per group) at 18 months. Bone levels were measured as the distance from the cemento-enamel junction to the alveolar bone crest from 14 predetermined maxillary buccal sites. The BALB/c wild-type and $T L R 2^{-/}$mice had similar bone levels in their youth at 8 weeks. Both groups showed greater bone loss when aged. However, $T L R 2^{-1-}$ mice showed less age-associated change compared to the wild-types (Figure 4).

Thus, $T L R 2^{-/}$mice experience less age-associated periodontal bone loss relative to the wild-type controls. 
BALBc WT vs. TLR2 ${ }^{-1-}$ (18-mo old)


Figure 4. Age-associated periodontal bone loss in Normal and $T_{L} \mathbf{R}^{-/}$mice. The total distance $(\mathrm{mm})$ from the cementoenamel junction (CEJ) to the alveolar bone crest $(A B C)$ from 14 predetermined maxillary buccal sites in each sample was measured on 5 young ( 8 week-old) and 16 old (18 month-old) mice for each group. Greater CEJ-ABC distances indicate greater bone loss. (Top) Each point corresponds to the sum of these distances for each sample. Old $T L R 2^{-/-}$mice 
exhibited less $\left({ }^{*} p<0.01\right)$ bone loss compared with age-matched BALB/c wildtype mice. (Bottom) The average changes in CEJ-ABC distances from young to old mice for BALB/c wild-type and $T L R 2^{-/}$mice. The $T L R 2^{-/-}$mice showed less $\left(^{*} p\right.$ $<0.01)$ age-associated change relative to the wild-type controls. Data are means $\pm \mathrm{SD}$ (Bottom). 

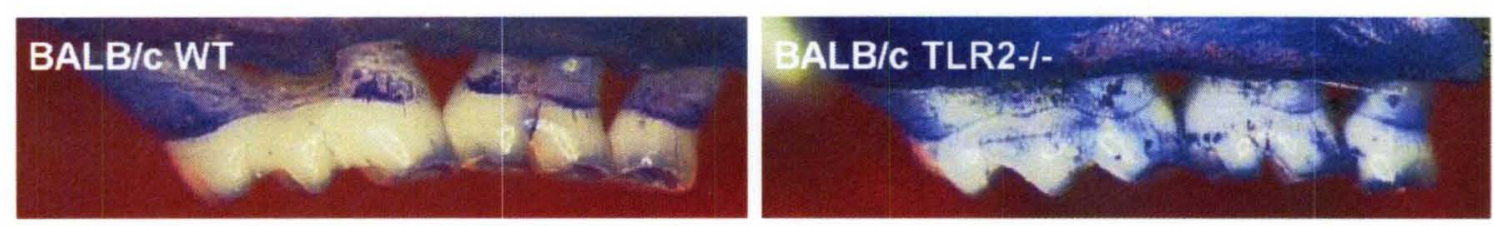

Figure 5. Representative images of CEJ-ABC distances in wild-type and $T L R 2^{-/-}$mice at 18 months. Representative images of defleshed maxillae showing that $T L R 2^{-/}$mice (right) develop less age-associated bone loss compared to BALB/c wild-type controls (left). Periodontal bone levels were assessed under a dissecting microscope $(x 40)$ fitted with a video image marker measurement system (VIA-170K; Boeckeler Instruments) standardized for measurements in millimeters. The distance from the cementoenamel junction $(C E J)$ to the alveolar bone crest $(A B C)$ was measured on 14 predetermined points on the buccal surfaces of the maxillary molars. 
ORAL ANAEROBIC BACTERIAL LOAD IS INCREASED IN AGED TLR2- MICE

Inflammation can kill bacteria when operating as intended, but can also contribute to their persistence by providing nutrients. We investigated the influence of TLR2 deficiency on oral microbial burden to determine the effects of the inflammatory response in this respect. To assess the oral microbial burden, the murine oral cavity was sampled for 15 seconds using sterile paperpoints in contact with the gumlines. Serial dilutions of the paperpoint extracts were inoculated on GAM blood agar plates and grown anaerobically at $37^{\circ} \mathrm{C}$ for one week for CFU determination. $T L R 2^{-/}$mice were less able to clear these bacteria from the oral cavity than their BALB/c wild-type controls (Figure 6). 


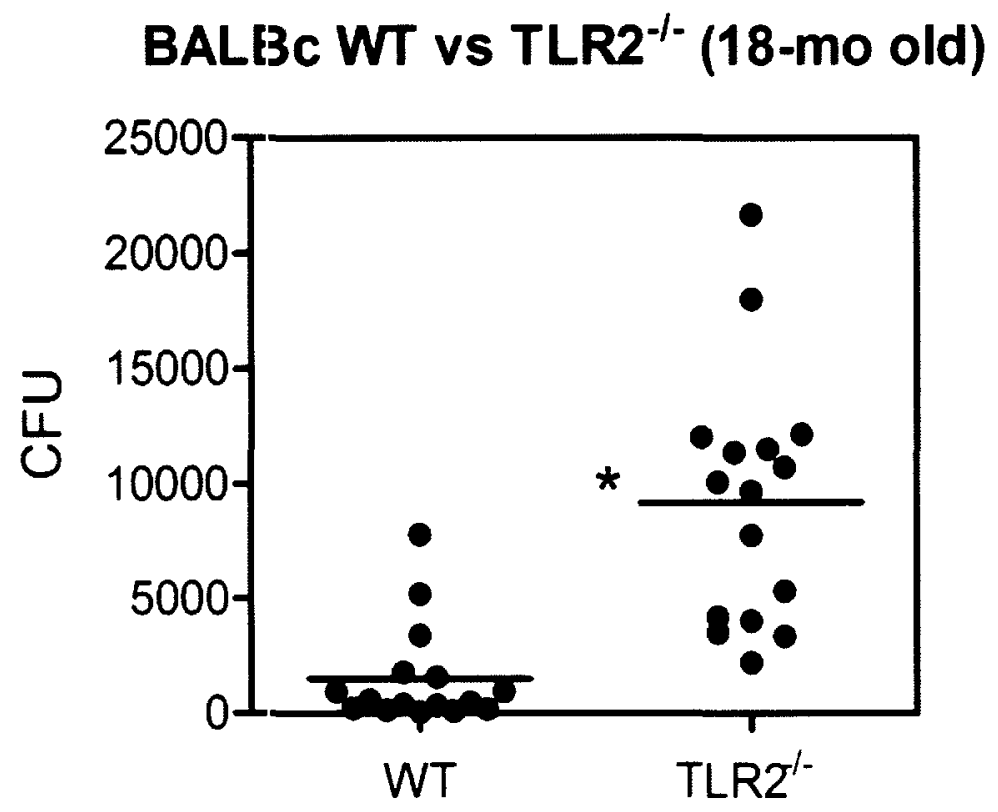

Figure 6. Oral anaerobic bacterial load is increased by TLR2 deficiency in aged mice. The murine oral cavities of 16 old (18 months) BALB/c wild-type and 16 old $T L R 2^{--}$mice were each sampled for 15 seconds using sterile paperpoints in contact with the gumlines. Serial dilutions of the paperpoint extracts were inoculated on GAM blood agar plates and grown anaerobically at $37^{\circ} \mathrm{C}$ for one week for CFU determination. The TLR2 $2^{--}$mice showed greater $(p<0.01)$ CFU than their age-matched wild-type mice. 


\section{GINGIVAL EXPRESSION OF INNATE INFLAMMATORY MEDIATORS INDICATES LESSENED INFLAMMATION IN AGED TLR2 ${ }^{-/}$MICE}

To determine inflammatory mechanisms of the innate immune system influenced by TLR2 deficiency in aged mice, we investigated the expression of innate receptors, adapters, and cytokines involved in inflammation in the gingivae of the aged (18 months) BALB/c wild-type and $T L R 2^{-/}$mice. Quantitative realtime PCR was used to determine gingival mRNA expression levels for the indicated receptors (normalized against GAPDH mRNA levels). This data shows expression levels in the gingivae of 18 -month old $T L R 2^{--}$mice relative to their wild-type controls (Figure 7). The mRNA expression of inflammatory markers was overall reduced in the old $T L R 2^{-/-}$mice compared with their age-matched BALB/c wild-type controls. Those molecules of particular interest which were expressed at lower levels in the $T L R 2^{-/}$mice included TLR1, TLR6, CD14, MyD88, IL-1 $\beta$, and RANKL (see Discussion). 


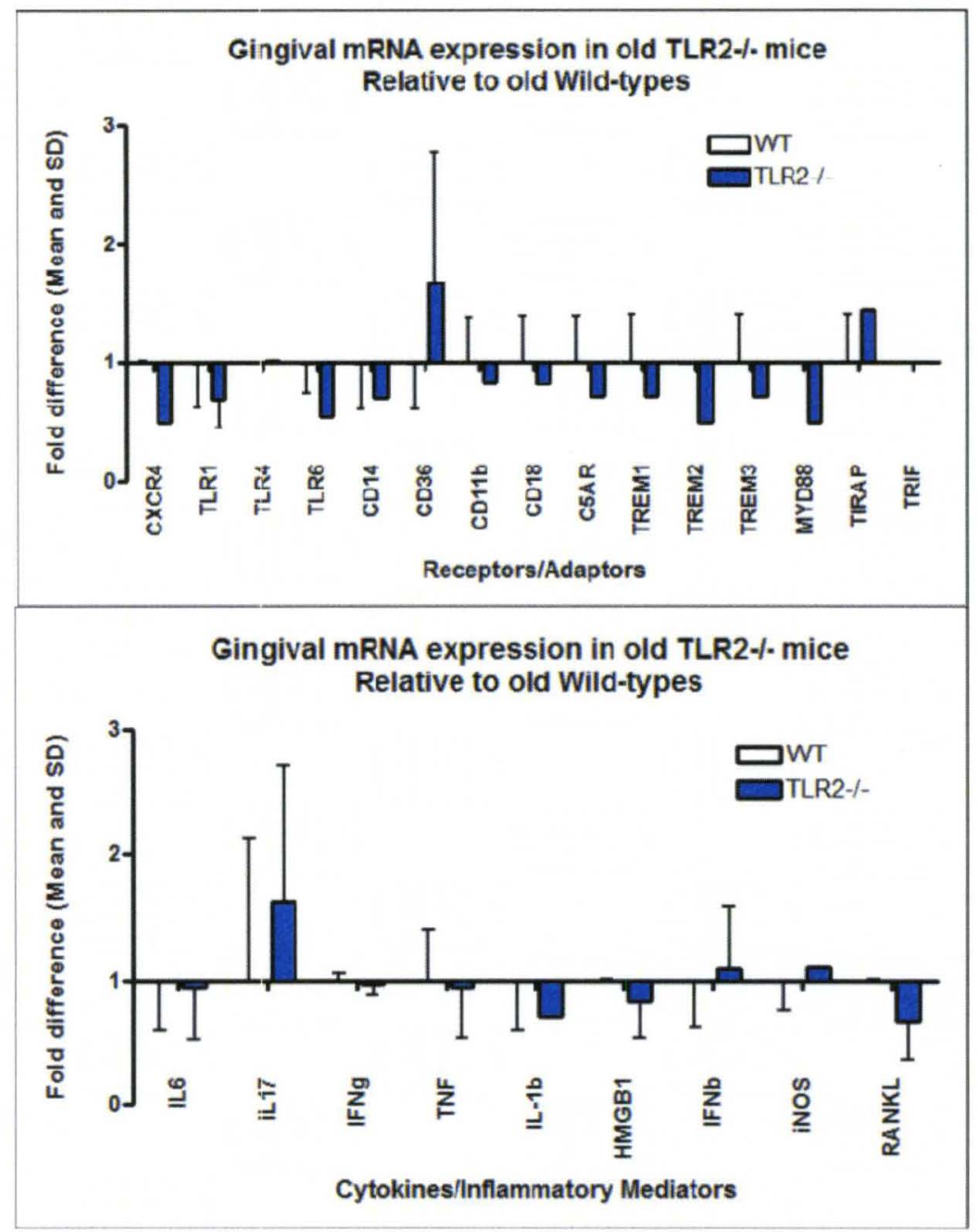

Figure 7. mRNA expressions in the gingivae of old $T L R 2^{-/-}$mice relative to wild-type controls. Quantitative real-time PCR was used to determine gingival mRNA expression levels for the indicated innate receptors and adapters (Top), and inflammatory markers (Bottom). The gingival tissue used was excised from around the maxillary molars of aged (18 months) $T L R 2^{-/}$mice and aged BALB/C wild-type mice. Results are shown as fold change of aged $T L R 2^{--}$mice relative to BALB/c wild-type mice. Each data point represents mean \pm SD of 3 separate expression values, corresponding to qPCR analysis of total gingival RNA from individual mice. 
MYD88 ${ }^{-\alpha}$ MICE DEVELOP LESS AGE-ASSOCIATED BONE LOSS THAN WILDTYPE CONTROLS

Mice develop naturally occurring periodontitis as a function of age. MyD88 is a major signaling adaptor acting downstream of TLR2, which was found to be differentially upregulated in the gingivae of aged mice as compared to young controls. Therefore, we investigated whether MyD88 deficiency attenuated ageassociated periodontal bone loss. $\mathrm{C} 57 \mathrm{BL} / 6$ and $M y D 88^{-/-}$mice were raised under specific-pathogen-free conditions, and then sacrificed at two time points: the young group ( 5 mice per group) at 8 weeks, and the old ( 9 mice per group) at 18 months. Bone levels were measured as the distance from the cemento-enamel junction to the alveolar bone crest from 14 predetermined maxillary buccal sites. The C57BL/6 wild-type and $M y D 88^{-/}$mice had similar bone levels in their youth at 8 weeks. Both groups showed greater bone loss when aged. However, $M y D 88^{-/}$mice showed less age-associated change compared to the wild-types (Figure 8). Thus, $M y D 88^{--}$mice experience less age-associated periodontal bone loss relative to the wild-type controls. 


\section{C57BL/6 WT vs. MyD88-1- $(18-m o$ old $)$}
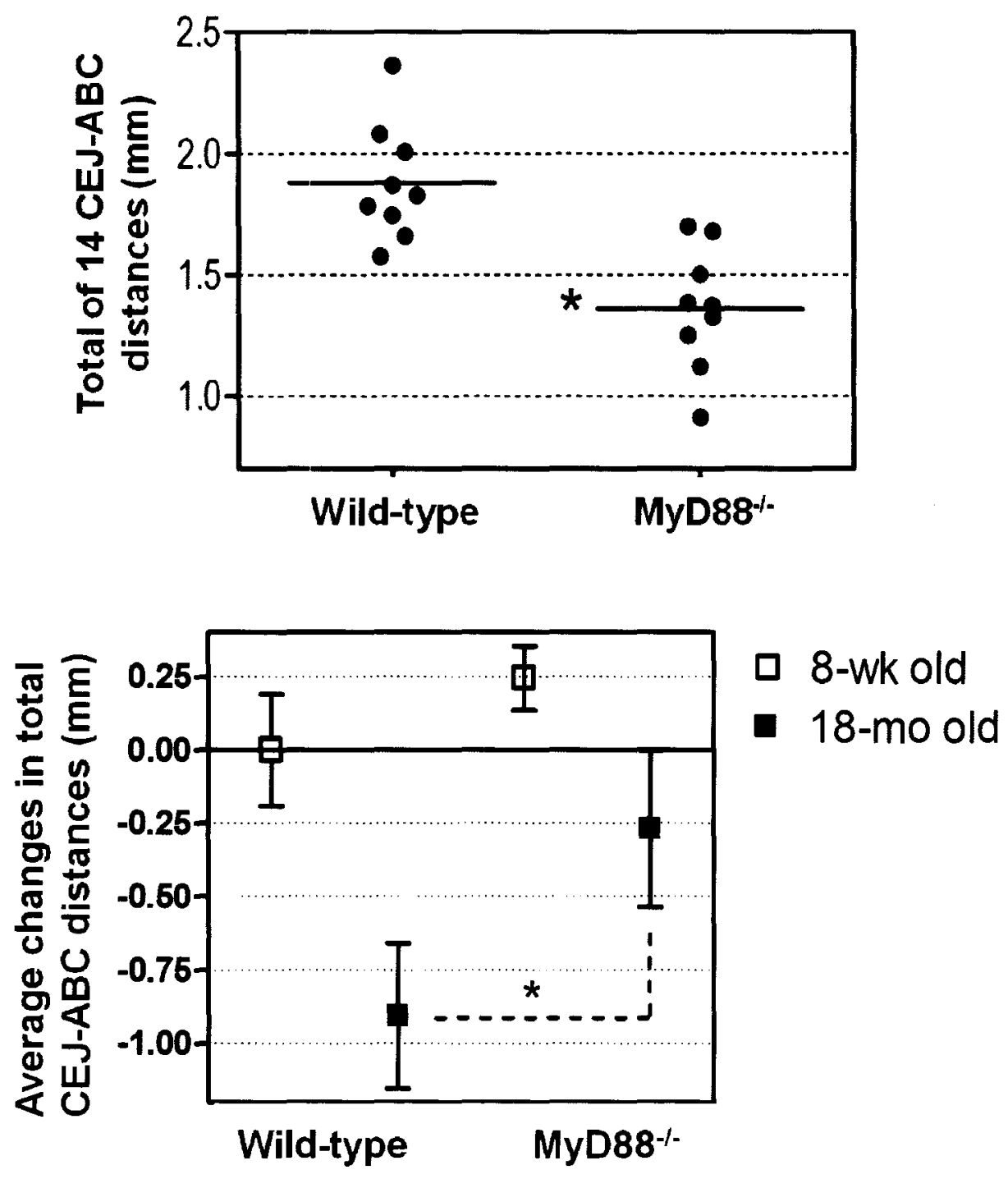

Figure 8. Age-associated periodontal bone loss in Normal and MyD88 mice. The total distance $(\mathrm{mm})$ from the cementoenamel junction (CEJ) to the alveolar bone crest $(A B C)$ from 14 predetermined maxillary buccal sites in each sample was measured on 5 young ( 8 week-old) and 9 old (18 month-old) mice for each group. Greater CEJ-ABC distances indicate greater bone loss. (Top) Each point corresponds to the sum of these distances for each sample. Old 
$M y D 88^{-/}$mice exhibited less $\left({ }^{*} p<0.01\right)$ bone loss compared with age-matched C57BL/6 wild-type mice. (Bottom) The average changes in CEJ-ABC distances from young to old mice for C57BL/6 wild-type and $M y D 88^{-/-}$mice. The MyD88 ${ }^{-1-}$ mice showed less $\left({ }^{*} p<0.01\right)$ age-associated change relative to the wild-type controls. Data are means \pm SD (Bottom). 
18 months old

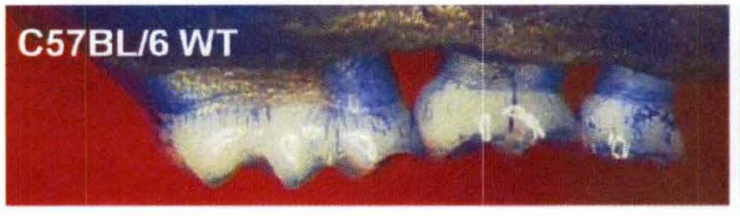

\section{C57BL/6 MyD88-/-}

Figure 9. Representative images of CEJ-ABC distances in wild-type and $M y 8^{-/}$mice at 18 months. Representative images of defleshed maxillae showing that $M y D 88^{--}$mice (right) develop less age-associated bone loss compared to C57BL/6 wild-type controls (left). Periodontal bone levels were assessed under a dissecting microscope (x40) fitted with a video image marker measurement system (VIA-170K; Boeckeler Instruments) standardized for measurements in millimeters. The distance from the cementoenamel junction (CEJ) to the alveolar bone crest $(A B C)$ was measured on 14 predetermined points on the buccal surfaces of the maxillary molars. 
ORAL ANAEROBIC BACTERIAL LOAD IS DECREASED IN AGED MYD88 ${ }^{-1}$ MICE

Inflammation can kill bacteria when operating as intended, but can also contribute to their persistence by providing nutrients. We investigated the influence of MyD88 deficiency on oral microbial burden to determine the effects of the inflammatory response in this respect. To assess the oral microbial burden, the murine oral cavity was sampled for 15 seconds using sterile paperpoints in contact with the gumlines. Serial dilutions of the paperpoint extracts were inoculated on GAM blood agar plates and grown anaerobically at $37^{\circ} \mathrm{C}$ for one week for $\mathrm{CFU}$ determination. $\mathrm{MyD} 88^{-/}$mice were able to clear these bacteria from the oral cavity more effectively than their C57BL/6 wild-type controls (Figure 10). 


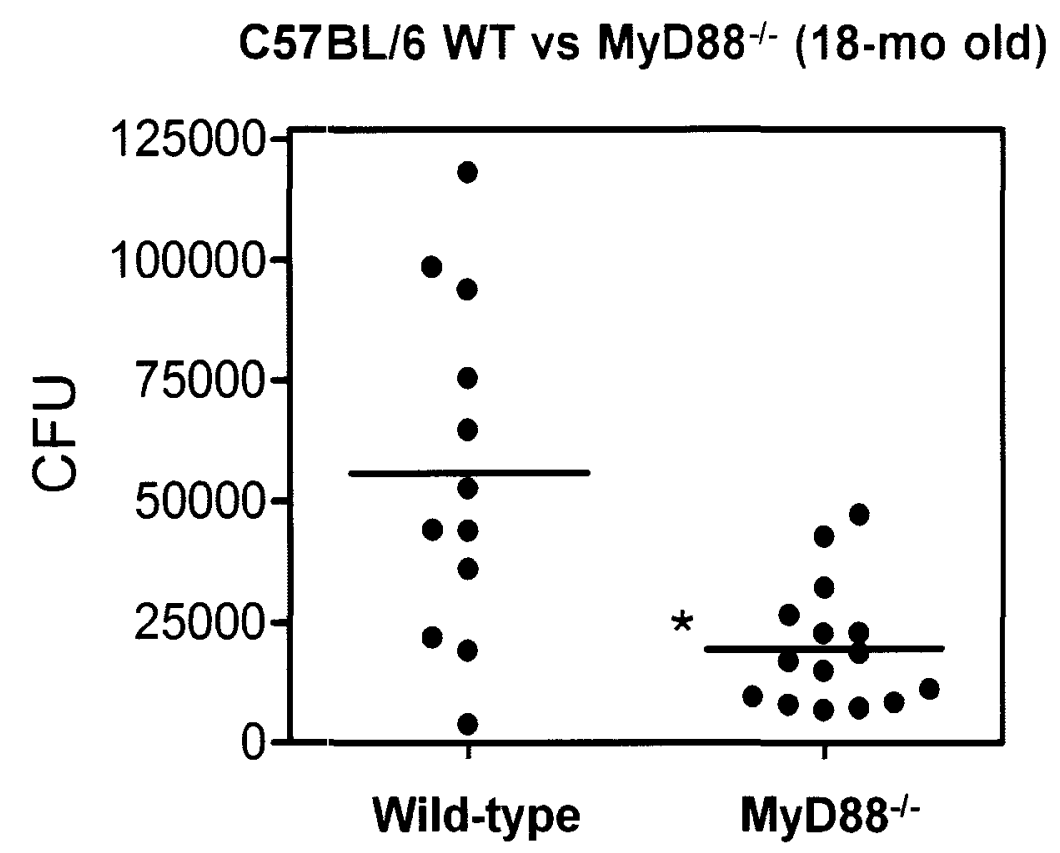

Figure 10. Oral anaerobic bacterial load is decreased by MyD88 deficiency in aged mice. The murine oral cavities of 12 old (18 months) C57BL/6 wild-type and 15 old $M y D 88^{-1-}$ mice were each sampled for 15 seconds using sterile paperpoints in contact with the gumlines. Serial dilutions of the paperpoint extracts were inoculated on GAM blood agar plates and grown anaerobically at $37^{\circ} \mathrm{C}$ for one week for CFU determination. The $M y D 88^{-\alpha}$ mice showed greater ( $p$ $<0.01)$ CFU than their age-matched wild-type mice. 
GINGIVAL EXPRESSION OF INNATE INFLAMMATORY MEDIATORS

INDICATES ACTIVATION OF TRIF-DEPENDENT PATHWAY IN AGED

MYD88 $8^{-/-}$MICE

To determine inflammatory mechanisms of the innate immune system influenced by MyD88 deficiency in aged mice, we investigated the expression of innate receptors, adapters, and cytokines involved in inflammation in the gingivae of the aged (18 months) C57BL/6 wild-type and $M y D 88^{-/}$mice. Quantitative realtime PCR was used to determine gingival mRNA expression levels for the indicated receptors (normalized against GAPDH mRNA levels). This data shows expression levels in the gingivae of 18 -month old $M y D 88^{-/}$mice relative to their wild-type controls (Figure 11). Of particular interest was the increased mRNA expression of TLR4, TRIF, and IFN $\beta$, in the old $M y D 88^{-/}$mice compared with wild-type controls, which indicate activation of the TRIF-dependent pathway. Also of interest were the increased expression of RANKL and the decreased expression of IL-1 $\beta$ in the old $M y D 88^{-/}$mice compared with wild-type controls (see Discussion). 


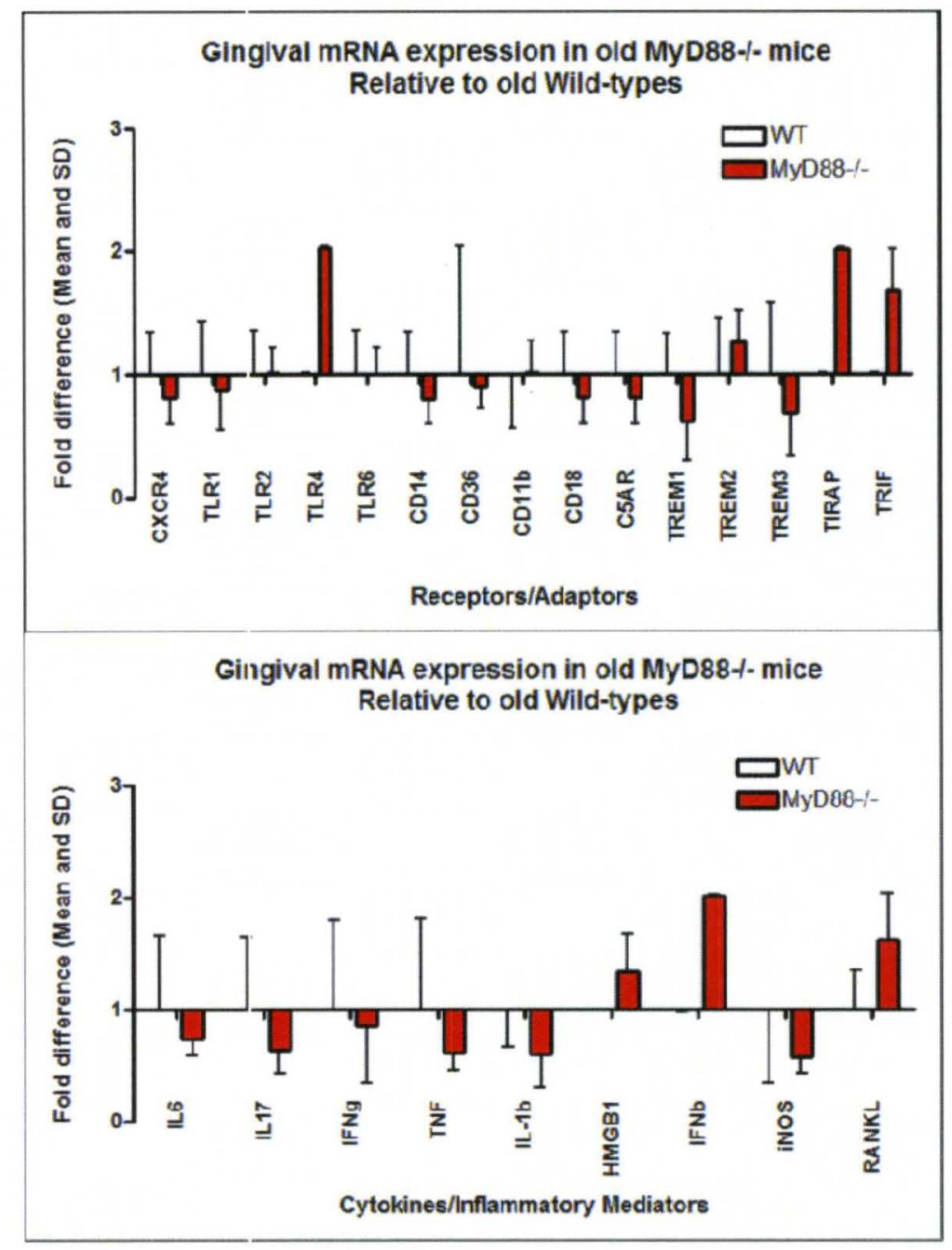

Figure 11. mRNA expressions in the gingivae of old $M y D 88^{-/-}$mice relative to wild-type controls. Quantitative real-time PCR was used to determine gingival mRNA expression levels for the indicated innate receptors and adapters (Top), and inflammatory markers (Bottom). The gingival tissue used was excised from around the maxillary molars of aged (18 months) MyD88 ${ }^{-/}$mice and aged C57BL/6 wild-type mice. Results are shown as fold change of aged MyD88mice relative to $\mathrm{C} 57 \mathrm{BL} / 6$ wild-type mice. Each data point represents mean \pm SD of 3 separate expression values, corresponding to $\mathrm{QPCR}$ analysis of total gingival RNA from individual mice. 


\section{CHAPTER IV:}

\section{DISCUSSION AND CONCLUSIONS}

\section{DISCUSSION}

We found that $T L R 2^{-/-}$and $M Y D 88^{--}$mice developed less age-associated periodontal bone loss compared with wild-type controls (Figures 4,8). Therefore, TLR2 and MyD88 must contribute to age-associated periodontal bone loss. We were unable to determine which molecule contributes more significantly because the $T L R 2^{-/}$mice were of $B A L B / c$ background whereas the $M y D 88^{--}$mice were of C57BL/6 background. The $T L R 2^{--}$mice were backcrossed onto a BALB/c genetic background to accommodate other projects by our lab.

Past studies have shown that $T L R 2^{--}$mice are protected from periodontal bone loss in relatively acute models using oral gavage with known human periodontal pathogens (Burns et al., 2006). The novelty of these results is that they derive from a truly chronic aging model of periodontitis, which takes into consideration any cell-intrinsic defects of the immune system and the tissue environment in the aged mice. Therefore, this is a step closer towards what may occur in elderly humans, and strengthens the case for these molecules as therapeutic targets in age-associated periodontitis. 
Inflammation is a "double-edged sword" in the sense that it can kill pathogens when operating as intended, but, in addition to causing tissue damage, can actually provide nutrients essential to the persistence of certain bacteria (Delima and Van Dyke, 2003), thus counteracting the intended effect. Our CFU results give us insights into what may have occurred in this respect.

The oral anaerobic bacterial load was higher in the $T L R 2^{-/}$mice compared with wild-type controls (Figure 6), indicating that TLR2 signaling improves bacterial clearance. Despite the more efficient TLR2-mediated bacterial killing by our BALB/c wild-type mice, the collateral damage of the inflammatory response still resulted in tissue damage, evidenced by the increased bone loss of these wild-types. Perhaps some of these anaerobes are cleared effectively, yet the most persistent pathogens are prolonging the ineffective inflammation.

Surprisingly, the MyD88 $8^{-\alpha}$ mice showed the opposite trend from the $T L R 2^{-/-}$ mice. MyD88 deficiency improved bacterial clearance (Figure 10), suggesting that other immune pathways may work more effectively in the absence of MyD88 signaling. Given the vast impact of MyD88 signaling, compensatory up-regulation of other immune pathways with bactericidal effects is possible. Perhaps activation of the MyD88-independent pathway (Figure 11; see below) is providing an effective means of clearing these bacteria, either through an effective lowgrade inflammatory response or some other means. 
It is also possible that a significant lack of inflammation in the $M y D 88^{-1-}$ mice is starving the bacteria of nutrients required for their growth and reproduction.

These CFU results may involve differing oral bacterial compositions responsible for innate immune activation, as well as their differing resistances to the host response; we did not identify these bacterial species, although they were all anaerobes. It is possible that these bacterial profiles differed between the $\mathrm{BALB} / \mathrm{C}$ and $\mathrm{C} 57 \mathrm{BL} / 6$ mice, perhaps due to their different genetic backgrounds; a potential source of error, given the vastly different CFU counts between the BALB/C and C57BL/6 wild-type mice. Nevertheless, the pathogens that are persistent in the C57BL/6 wild-type mice are triggering the chronic inflammation responsible for their increased bone loss.

For the $T L R 2^{-/}$mice, the quantitative real-time PCR suggests an overall decreased inflammatory response compared to the wild-types (Figure 7). In the $T L R 2^{-/}$mice, mRNA expressions for CD14, TLR1 and TLR6 were all expressed at lower levels, consistent with the fact that they all associate with TLR2 for inflammatory signaling. MyD88 mRNA was also lower, indicating that TLR2 signals through MyD88 in the wild-types. IL-1 $\beta$ and RANKL, both bone-resorptive cytokines, also expressed lower levels in the $T L R 2^{-/-}$mice. These results support an increased inflammatory state in normal BALB/c wild-type mice, and thus the increased bone loss. 
The qPCR results for the $M y D 88^{-/}$mice also indicated a lower expression of IL-1 $\beta$ compared to wild-types (Figure 11). Interestingly, unlike the $T L R 2^{-\gamma}$ mice, RANKL was expressed at a higher level in the $M y D 88^{-/}$mice, indicating perhaps, distinct effects of MyD88 deficiency and TLR2 deficiency on bone-resorptive mechanisms. The most obvious trend in these qPCR results, however, is the upregulation of the MyD88-independent pathway in the $M y D 88^{-/-}$mice, as evidenced by their increased mRNA expression of TLR4, TRIF, and IFN $\beta$. Thus, we can conclude that this pathway does not produce comparable inflammation or bone resorption compared to the MyD88-dependent signaling in the wild-type controls. 


\section{CONCLUSION}

In conclusion, we have shown that TLR2 and MyD88 contribute to periodontal bone loss in aged mice. Although their differential effects on bacterial burden and their influence on certain genes (e.g. RANKL) possibly indicate distinct bone-resorptive mechanisms, they both induce destructive effects. This suggests that these molecules may be potential targets for drug therapies in the treatment of age-associated periodontitis. This in turn, may reduce the risk of associated conditions in the growing elderly population. 


\section{REFERENCES}

Akashi-Takamura S, Miyake K (2008). TLR accessory molecules. Current Opinion in Immunology 20(4):420-425.

Asai Y, Ohyama Y, Gen K, Ogawa T (2001). Bacterial fimbriae and their peptides activate human gingival epithelial cells through Toll-like receptor 2. Infect Immun 69(12):7387-7395.

Asai $Y$, Jinno T, Ogawa $T$ (2003). Oral treponemes and their outer membrane extracts activate human gingival epithelial cells through toll-like receptor 2 . Infect Immun 71(2):717-725.

Baker PJ, Dixon M, Roopenian DC (2000). Genetic control of susceptibility to Porphyromonas gingivalis-induced alveolar bone loss in mice. Infect Immun 68(10):5864-5868.

Beertsen W, Willenborg M, Everts V, Zirogianni A, Podschun R, Schroder B et al. (2008). Impaired phagosomal maturation in neutrophils leads to periodontitis in lysosomal-associated membrane protein-2 knockout mice. J Immunol 180(1):475-482.

Brown J, Wang H, Hajishengallis GN, Martin M (2010). TLR-signaling Networks: An Integration of Adaptor Molecules, Kinases, and Cross-talk. J Dent Res.

Burns E, Bachrach G, Shapira L, Nussbaum G (2006). Cutting Edge: TLR2 is Required for the Innate Response to Porphyromonas gingivalis: Activation Leads to Bacterial Persistence and TLR2 Deficiency Attenuates Induced Alveolar Bone Resorption. The Journal of Immunology 177(12):8296-8300.

Cullinan MP, Ford PJ, Seymour GJ (2009). Periodontal disease and systemic health: current status. Australian Dental Journal 54(S62-S69.

Darveau RP, Arbabi S, Garcia I, Bainbridge B, Maier RV (2002). Porphyromonas gingivalis lipopolysaccharide is both agonist and antagonist for $\mathrm{p} 38$ mitogen-activated protein kinase activation. Infect Immun 70(4):1867-1873. 
Delima AJ, Van Dyke TE (2003). Origin and function of the cellular components in gingival crevice fluid. Periodontology 2000 31(1):55-76.

Dennison DK, Van Dyke TE (1997). The acute inflammatory response and the role of phagocytic cells in periodontal health and disease. Periodontol 2000 14(54-78.

Dounis G, Ditmyer MM, McClain MA, Cappelli DP, Mobley CC (2010). Preparing the Dental Workforce for Oral Disease Prevention in an Aging Population. Journal of Dental Education 74(10):1086-1094.

Fearon DT (1997). Seeking wisdom in innate immunity. Nature 388(6640):323-324.

Filoche S, Wong L, Sissons CH (2010). Oral Biofilms: Emerging Concepts in Microbial Ecology. Journal of Dental Research 89(1):8-18.

Folwaczny M, Glas J, TÖRÖK HP, Limbersky O, Folwaczny C (2004). Toll-like receptor (TLR) 2 and 4 mutations in periodontal disease. Clinical \& Experimental Immunology 135(2):330-335.

Franceschi C, BonafÈ M, Valensin S, Olivieri F, De Luca M, Ottaviani E et al. (2000). Inflammaging: An Evolutionary Perspective on Immunosenescence. Annals of the New York Academy of Sciences 908(1):244-254.

Fransson C, Berglundh T, Lindhe J (1996). The effect of age on the development of gingivitis. Journal of Clinical Periodontology 23(4):379-385.

Fulop T, Larbi A, Douziech N, Fortin C, Guérard K-P, Lesur O et al. (2004). Signal transduction and functional changes in neutrophils with aging. Aging Cell 3(4):217-226.

Gaffen SL, Hajishengallis G (2008). A New Inflammatory Cytokine on the Block: Re-thinking Periodontal Disease and the Th1/Th2 Paradigm in the Context of Th17 Cells and IL-17. Journal of Dental Research 87(9):817-828.

Garlet GP, Cardoso CR, Silva TA, Ferreira BR, Avila-Campos MJ, Cunha FQ et al. (2006). Cytokine pattern determines the progression of experimental periodontal disease induced by Actinobacillus actinomycetemcomitans through the modulation of MMPs, RANKL, and their physiological inhibitors. Oral Microbiol Immunol 21(1):12-20.

Gemmell E, Yamazaki K, Seymour GJ (2002). Destructive periodontitis lesions are determined by the nature of the lymphocytic response. Crit Rev Oral Biol Med 13(1):17-34. 
Gemmell E, Seymour GJ (2004). Immunoregulatory control of Th1/Th2 cytokine profiles in periodontal disease. Periodontol 2000 35(21-41.

Gomez CR, Nomellini V, Faunce DE, Kovacs EJ (2008). Innate immunity and aging. Experimental Gerontology 43(8):718-728.

Goriely S, Neurath MF, Goldman M (2008). How microorganisms tip the balance between interleukin-12 family members. Nat Rev Immuno/ 8(1):81-86.

Gowen M, Mundy GR (1986). Actions of recombinant interleukin 1, interleukin 2, and interferongamma on bone resorption in vitro. J Immunol 136(7):2478-2482.

Gowen M, Nedwin GE, Mundy GR (1986). Preferential inhibition of cytokine-stimulated bone resorption by recombinant interferon gamma. J Bone Miner Res 1(5):469-474.

Graves DT, Fine D, Teng YT, Van Dyke TE, Hajishengallis G (2008). The use of rodent models to investigate host-bacteria interactions related to periodontal diseases. $J$ Clin Periodontol 35(2):89-105.

Graves DT, Li J, Cochran DL (2011). Inflammation and uncoupling as mechanisms of periodontal bone loss. J Dent Res 90(2):143-153.

Hajishengallis G, Sojar H, Genco RJ, DeNardin E (2004). Intracellular signaling and cytokine induction upon interactions of Porphyromonas gingivalis fimbriae with pattern-recognition receptors. Immunol Invest 33(2):157-172.

Hajishengallis G, Shakhatreh MA, Wang M, Liang S (2007). Complement receptor 3 blockade promotes IL-12-Mediated Clearance of Porphyromonas gingivalis and Negates Its Virulence In Vivo. J Immunol 179(4):2359-2367.

Hajishengallis G, Wang M, Liang S, Triantafilou M, Triantafilou K (2008). Pathogen induction of CXCR4/TLR2 cross-talk impairs host defense function. Proc Nat/ Acad Sci U S A 105(36):1353213537.

Hajishengallis $G$ (2009). Porphyromonas gingivalis-host interactions: open war or intelligent guerilla tactics? Microbes infect 11(6-7):637-645. 
Hajishengallis G, Wang $M$, Liang $S$ (2009). Induction of distinct TLR2-mediated proinflammatory and proadhesive signaling pathways in response to Porphyromonas gingivalis fimbriae. $J$ Immunol 182(11):6690-6696.

Hajishengallis G (2010). Too old to fight? Aging and its toll on innate immunity. Molecular Oral Microbiology 25(1):25-37.

Hajishengallis G, Lambris JD (2011). Microbial manipulation of receptor crosstalk in innate immunity. Nat Rev Immunol 11(3):187-200.

Hajishengallis G, Liang S, Payne Mark A, Hashim A, Jotwani R, Eskan Mehmet A et al. (2011). Low-Abundance Biofilm Species Orchestrates Inflammatory Periodontal Disease through the Commensal Microbiota and Complement. Cell Host \&amp; Microbe 10(5):497-506.

Hasan U, Chaffois C, Gaillard C, Saulnier V, Merck E, Tancredi S et al. (2005). Human TLR10 is a functional receptor, expressed by $B$ cells and plasmacytoid dendritic cells, which activates gene transcription through MyD88. J Immunol 174(5):2942-2950.

Hirschfeld M, Weis JJ, Toshchakov V, Salkowski CA, Cody MJ, Ward DC et al. (2001). Signaling by toll-like receptor 2 and 4 agonists results in differential gene expression in murine macrophages. Infect Immun 69(3):1477-1482.

Horwood NJ, Elliott J, Martin TJ, Gillespie MT (2001). IL-12 alone and in synergy with IL-18 inhibits osteoclast formation in vitro. J Immunol 166(8):4915-4921.

Hou L, Sasaki H, Stashenko P (2000). Toll-like receptor 4-deficient mice have reduced bone destruction following mixed anaerobic infection. Infect Immun 68(8):4681-4687.

Iwasaki A, Medzhitov R (2004). Toll-like receptor control of the adaptive immune responses. Nat Immunol 5(10):987-995.

Kawai T, Adachi O, Ogawa T, Takeda K, Akira S (1999). Unresponsiveness of MyD88-Deficient Mice to Endotoxin. Immunity 11(1):115-122.

Kawai T, Akira S (2007). TLR signaling. Seminars in Immunology 19(1):24-32.

Kikkert R, Laine ML, Aarden LA, Van Winkelhoff AJ (2007). Activation of toll-like receptors 2 and 4 by gram-negative periodontal bacteria. Oral Microbiology and Immunology 22(3):145-151. 
Kinane DF, Hajishengallis $G$ (2009). Polymicrobial infections, biofilms, and beyond. Journal of Clinical Periodontology 36(5):404-405.

Kumar $\mathrm{H}$, Kawai T, Akira S (2009a). Pathogen recognition in the innate immune response. Biochem J 420(1):1-16.

Kumar H, Kawai T, Akira S (2009b). Toll-like receptors and innate immunity. Biochemical and Biophysical Research Communications 388(4):621-625.

Lee W, Aitken S, Sodek J, McCulloch CA (1995). Evidence of a direct relationship between neutrophil collagenase activity and periodontal tissue destruction in vivo: role of active enzyme in human periodontitis. J Periodontal Res 30(1):23-33.

Liang S, Domon H, Hosur KB, Wang M, Hajishengallis G (2009). Age-related alterations in innate immune receptor expression and ability of macrophages to respond to pathogen challenge in vitro. Mechanisms of Ageing and Development 130(8):538-546.

Liang S, Hosur KB, Domon H, Hajishengallis G (2010). Periodontal inflammation and bone loss in aged mice. Journal of Periodontal Research 45(4):574-578.

Liang S, Krauss JL, Domon H, McIntosh ML, Hosur KB, Qu H et al. (2011). The C5a receptor impairs IL-12-dependent clearance of Porphyromonas gingivalis and is required for induction of periodontal bone loss. J Immunol 186(2):869-877.

Lorenzo J, Horowitz M, Choi Y (2008). Osteoimmunology: Interactions of the Bone and Immune System. Endocrine Reviews 29(4):403-440.

McCoy CE, O'Neill LA (2008). The role of toll-like receptors in macrophages. Front Biosci 13(6270.

Mori Y, Yoshimura A, Ukai T, Lien E, Espevik T, Hara Y (2003). Immunohistochemical localization of Toll-like receptors 2 and 4 in gingival tissue from patients with periodontitis. Oral Microbiology and Immunology 18(1):54-58.

Nan-ping W (2006). Aging of the Immune System: How Much Can the Adaptive Immune System Adapt? Immunity 24(5):495-499.

Niederman R, Westernoff T, Lee C, Mark LL, Kawashima N, Ullman-Culler M et al. (2001). Infection-mediated early-onset periodontal disease in P/E-selectin-deficient mice. J Clin Periodontol 28(6):569-575. 
Nussbaum G, Ben-Adi S, Genzler T, Sela M, Rosen G (2009). Involvement of Toll-like receptors 2 and 4 in the innate immune response to Treponema denticola and its outer sheath components. Infect Immun 77(9):3939-3947.

O'Neill LAJ, Bowie AG (2007). The family of five: TIR-domain-containing adaptors in Toll-like receptor signalling. Nat Rev Immunol 7(5):353-364.

Oliver RC, Brown $\sqcup$, Loe $H$ (1998). Periodontal diseases in the United States population. J Periodontol 69(2):269-278.

Re F, Strominger JL (2001). Toll-like receptor 2 (TLR2) and TLR4 differentially activate human dendritic cells. J Biol Chem 276(40):37692-37699.

Ren L, Leung WK, Darveau RP, Jin L (2005). The expression profile of lipopolysaccharide-binding protein, membrane-bound CD14, and toll-like receptors 2 and 4 in chronic periodontitis. $J$ Periodontol 76(11):1950-1959.

Ruby J, Rehani K, Martin M (2007). Treponema denticola activates mitogen-activated protein kinase signal pathways through Toll-like receptor 2. Infect Immun 75(12):5763-5768.

Sharma A, Inagaki S, Honma K, Sfintescu C, Baker PJ, Evans RT (2005). Tannerella forsythiainduced alveolar bone loss in mice involves leucine-rich-repeat BspA protein. J Dent Res 84(5):462-467.

Shaw AC, Joshi S, Greenwood H, Panda A, Lord JM (2010). Aging of the innate immune system. Current Opinion in Immunology 22(4):507-513.

Shimazu R, Akashi S, Ogata H, Nagai Y, Fukudome K, Miyake K et al. (1999). MD-2, a molecule that confers lipopolysaccharide responsiveness on Toll-like receptor 4. J Exp Med 189(11):17771782 .

Socransky SS, Haffajee AD (2005). Periodontal microbial ecology. Periodontol 2000 38(135-187.

Solana R, Pawelec G, Tarazona R (2006). Aging and Innate Immunity. Immunity 24(5):491-494.

Stout RD, Suttles J (2005). Immunosenescence and macrophage functional plasticity: dysregulation of macrophage function by age-associated microenvironmental changes. Immunol Rev 205(60-71. 
Sun Y, Shu R, Li C-L, Zhang M-Z (2010). Gram-Negative Periodontal Bacteria Induce the Activation of Toll-Like Receptors 2 and 4, and Cytokine Production in Human Periodontal Ligament Cells. Journal of Periodontology 81(10):1488-1496.

Takeuchi O, Hoshino K, Kawai T, Sanjo H, Takada H, Ogawa T et al. (1999). Differential roles of TLR2 and TLR4 in recognition of gram-negative and gram-positive bacterial cell wall components. Immunity 11(4):443-451.

Takeuchi O, Takeda K, Hoshino K, Adachi O, Ogawa T, Akira S (2000). Cellular responses to bacterial cell wall components are mediated through MyD88-dependent signaling cascades. Int Immunol 12(1):113-117.

Takeuchi O, Kawai T, Muhlradt PF, Morr M, Radolf JD, Zychlinsky A et al. (2001). Discrimination of bacterial lipoproteins by Toll-like receptor 6. Int Immunol 13(7):933-940.

Takeuchi O, Sato S, Horiuchi T, Hoshino K, Takeda K, Dong Z et al. (2002). Cutting edge: role of Toll-like receptor 1 in mediating immune response to microbial lipoproteins. J Immunol 169(1):10-14.

Teng Y-TA (2003). The Role of Acquired Immunity and Periodontal Disease Progression. Critical Reviews in Oral Biology \& Medicine 14(4):237-252.

Teng YT (2006). Protective and destructive immunity in the periodontium: Part 1--innate and humoral immunity and the periodontium. J Dent Res 85(3):198-208.

Ukai T, Yumoto H, Gibson FC, III, Genco CA (2008). Macrophage-Elicited Osteoclastogenesis in Response to Bacterial Stimulation Requires Toll-Like Receptor 2-Dependent Tumor Necrosis Factor-Alpha Production. Infect Immun 76(2):812-819.

Underhill DM, Gantner B (2004). Integration of Toll-like receptor and phagocytic signaling for tailored immunity. Microbes and Infection 6(15):1368-1373.

van der Velden $U$ (1991). The onset age of periodontal destruction. Journal of Clinical Periodontology 18(6):380-383.

Wang $M$, Shakhatreh MA, James D, Liang S, Nishiyama S, Yoshimura F et al. (2007). Fimbrial proteins of porphyromonas gingivalis mediate in vivo virulence and exploit TLR2 and complement receptor 3 to persist in macrophages. J Immunol 179(4):2349-2358. 
Wang M, Krauss JL, Domon H, Hosur KB, Liang S, Magotti P et al. (2010). Microbial Hijacking of Complement-Toll-Like Receptor Crosstalk. Sci Signal 3(109):ra11-.

Wingrove JA, DiScipio RG, Chen Z, Potempa J, Travis J, Hugli TE (1992). Activation of complement components $\mathrm{C} 3$ and $\mathrm{C} 5$ by a cysteine proteinase (gingipain-1) from Porphyromonas (Bacteroides) gingivalis. J Biol Chem 267(26):18902-18907.

Winker MA, DeAngelis CD (2010). Caring for an Aging Population. JAMA: The Journal of the American Medical Association 303(5):455-456.

Wright SD, Tobias PS, Ulevitch RJ, Ramos RA (1989). Lipopolysaccharide (LPS) binding protein opsonizes LPS-bearing particles for recognition by a novel receptor on macrophages. $J$ Exp Med 170(4):1231-1241.

Wright SD, Ramos RA, Tobias PS, Ulevitch RJ, Mathison JC (1990). CD14, a receptor for complexes of lipopolysaccharide (LPS) and LPS binding protein. Science 249(4975):1431-1433.

Yamamoto M, Sato S, Hemmi H, Hoshino K, Kaisho T, Sanjo H et al. (2003). Role of Adaptor TRIF in the MyD88-Independent Toll-Like Receptor Signaling Pathway. Science 301(5633):640-643.

Yamamoto M, Takeda K, Akira S (2004). TIR domain-containing adaptors define the specificity of TLR signaling. Molecular Immunology 40(12):861-868.

Yoshioka H, Yoshimura A, Kaneko T, Golenbock DT, Hara Y (2008). Analysis of the activity to induce toll-like receptor (TLR)2- and TLR4-mediated stimulation of supragingival plaque. $J$ Periodontol 79(5):920-928.

Zähringer $U$, Lindner $B$, Inamura S, Heine $H$, Alexander C (2008). TLR2 - promiscuous or specific? A critical re-evaluation of a receptor expressing apparent broad specificity. Immunobiology 213(3-4):205-224. 


\section{CURRICULUM VITAE}

NAME

ADDRESS

DOB

EDUCATION

TRAINING \& EXPERIENCE
Paul Anthony Ciero

224 E. Magnolia Avenue

Louisville, Kentucky 40208

Seoul, Republic of Korea; December 10, 1986

University at Buffalo, the State University of New York Bachelor of Science, Biomedical Sciences

June 2009 - cum laude

University of Louisville

Master of Science, Oral Biology

December 2011 (expected graduation)

University at Buffalo, the State University of New York Millard Fillmore College Certificate Program:

Regulatory Environment of Medical Devices and Implants Certificate of Completion - December 2008

Upstate Medical University, the State University of New York Department of Surgery: Cardiopulmonary and Critical Care Research Technologist - October 2009 - April 2010

University of Louisville School of Dentistry Center for Oral Health and Systemic Disease Summer Research Program 2011

CONFERENCE Ciero P, Liang S, Abe T, Li F, Hajishengallis G. Age-

PRESENTATIONS Associated Periodontal Bone Loss in Normal and TLR2- or MyD88-deficient Mice, Research!Louisville, October 10-14, 2011, Louisville, KY, USA

Ciero P, Liang S, Abe T, Li F, Hajishengallis G. AgeAssociated Periodontal Bone Loss in Normal and TLR2- or MyD88-deficient Mice, Gordon Research Conference on Periodontal Diseases, July 17-22, 2011, Davidson, NC, USA 
PUBLICATIONS Eskan A, Jotwani R, Abe T, Chmelar J, Lim J, Liang S, Ciero P, Krauss J, Li F, Rauner M, Hofbauer L, Choi E, Chung K, Hashim A, Curtis M, Chavakis T, Hajishengallis G. Developmental endothelial locus-1 (Del-1) is required for prevention of interleukin-17-mediated pathology. (Immunity, Under revision) 